\title{
Possible influence of anthropogenic aerosols on cirrus clouds and anthropogenic forcing
}

\author{
J. E. Penner ${ }^{1}$, Y. Chen ${ }^{2, *}$, M. Wang ${ }^{1}$, and X. Liu ${ }^{3}$ \\ ${ }^{1}$ University of Michigan, Department of Atmospheric, Oceanic and Space Sciences, Ann Arbor, USA \\ ${ }^{2}$ Jet Propulsion Laboratory, Pasadena California, USA \\ ${ }^{3}$ Pacific Northwest National Laboratory, Richland, Washington, USA \\ *now at: University of California, Irvine, California, USA
}

Received: 29 May 2008 - Published in Atmos. Chem. Phys. Discuss.: 22 July 2008

Revised: 22 December 2008 - Accepted: 22 December 2008 - Published: 3 February 2009

\begin{abstract}
Cirrus clouds have a net warming effect on the atmosphere and cover about $30 \%$ of the Earth's area. Aerosol particles initiate ice formation in the upper troposphere through modes of action that include homogeneous freezing of solution droplets, heterogeneous nucleation on solid particles immersed in a solution, and deposition nucleation of vapor onto solid particles. Here, we examine the possible change in ice number concentration from anthropogenic soot originating from surface sources of fossil fuel and biomass burning, from anthropogenic sulfate aerosols, and from aircraft that deposit their aerosols directly in the upper troposphere. We use a version of the aerosol model that predicts sulfate number and mass concentrations in 3modes and includes the formation of sulfate aerosol through homogeneous binary nucleation as well as a version that only predicts sulfate mass. The 3-mode version best represents the Aitken aerosol nuclei number concentrations in the upper troposphere which dominated ice crystal residues in the upper troposphere. Fossil fuel and biomass burning soot aerosols with this version exert a radiative forcing of -0.3 to $-0.4 \mathrm{Wm}^{-2}$ while anthropogenic sulfate aerosols and aircraft aerosols exert a forcing of -0.01 to $0.04 \mathrm{Wm}^{-2}$ and -0.16 to $-0.12 \mathrm{Wm}^{-2}$, respectively, where the range represents the forcing from two parameterizations for ice nucleation. The sign of the forcing in the mass-only version of the model depends on which ice nucleation parameterization is used and can be either positive or negative. The magnitude of
\end{abstract}

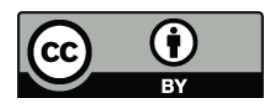

Correspondence to: J. E. Penner (penner@umich.edu) the forcing in cirrus clouds can be comparable to the forcing exerted by anthropogenic aerosols on warm clouds, but this forcing has not been included in past assessments of the total anthropogenic radiative forcing of climate.

\section{Introduction}

Cirrus clouds play an important role in climate. They trap of outgoing longwave radiation emitted by the Earth and atmosphere (a positive radiative effect) but this is partly compensated by their reflection of incoming solar radiation (a negative radiative effect). The particles that initiate ice formation include externally mixed sulfate aerosols, which may form haze particles and homogeneously freeze if temperatures are less than $235 \mathrm{~K}$ and supersaturations are greater than $145 \%$ with respect to ice (Koop et al., 1998). Laboratory studies of cirrus ice formation that relate ice nucleation to aerosol properties show that heterogeneous ice nucleation on mineral dust (e.g., Zuberi et al., 2002; Hung et al., 2003; Archuleta et al., 2005; Field et al., 2006; Möhler et al., 2006; Salam et al., 2006), and on soot (or black carbon, BC) particles (DeMott, 1990; DeMott et al., 1999; Gorbunov et al., 2001; Möhler et al., 2005) requires lower relative humidity over ice $\left(\mathrm{RH}_{i}\right)$ than homogeneous freezing on sulfate, while coating soot with sulfate can increase the nucleation thresholds to an ice saturation ratio of about 1.3 at $230 \mathrm{~K}$ to 1.5 at $185 \mathrm{~K}$ (Möhler et al., 2005). DeMott (2007) reported laboratory experiments with aircraft soot and aerosols produced from biomass burning which showed that aircraft and biomass soot particles required $\mathrm{RH}_{i}$ of close to $155 \%$ near $-55^{\circ} \mathrm{C}$. Thus,

Published by Copernicus Publications on behalf of the European Geosciences Union. 
these soot particles did not nucleate ice any easier than does sulfate aerosol when it freezes homogeneously. These conflicting results regarding the ability of soot to act as an ice nuclei (IN) make evaluation of the possible effects of aircraft soot or surface sources of soot on cirrus clouds highly uncertain. We explore these possibilities below.

Both sulfate aerosols and soot particles have increased as a result of fossil fuel use, biomass burning, and aircraft emissions. Therefore, there is the possibility that these increases may change ice number concentrations. The associated change in the effective radius of the ice crystals may lead to a change in the radiative impact of cirrus clouds. Here, we evaluate this possibility using a global model simulation of aerosol concentrations and off-line calculations of the effect of increases in particle concentrations on cirrus ice number concentration and radiative forcing.

If homogenous freezing of solution droplets is the dominant formation pathway for cold cirrus, then the number of ice crystals formed is expected to depend on the local updraft velocity and temperature, but is relatively insensitive to the number of aerosol particles (Notholt et al., 2005). This is because the number of soluble particles is not the limiting factor that determines the number of cirrus ice crystals (Kärcher and Lohmann, 2002). When heterogeneous nucleation is dominant, an increase in ice nuclei can increase the concentration of ice crystals formed. A pronounced indirect effect of aerosols on ice crystals is also possible when these two types of freezing aerosol particles compete during cloud formation. Adding efficient heterogeneous ice nuclei to a region where ice crystals form primarily through homogeneous freezing can lead to a marked suppression of the relative humidity with respect to ice $\left(\mathrm{RH}_{i}\right)$ and can thereby reduce ice crystal number densities. The magnitude of this effect depends on the updraft velocity, temperature, and the number and freezing properties of the ice nuclei (Jensen and Toon, 1994).

The importance of heterogeneous IN in cirrus cloud formation is unknown. Heymsfield and Miloshevich (1993) and Jensen and Toon (1994) concluded that homogeneous nucleation of supercooled drops was responsible for the occurrence of ice, and that aerosol number concentrations do not significantly affect cirrus ice crystal number and size. However, DeMott et al. $(1994,1997)$ argued that even a small number of heterogeneous ice nuclei would lower the maximum relative humidity within a cloud parcel, so that a change in the number of aerosol particles acting as heterogeneous IN could have a large impact on cirrus ice crystal number concentrations. It seems likely, based on the analysis of the Interhemispheric Differences in Cirrus Properties From Anthropogenic Emissions (INCA) measurements of $\mathrm{RH}_{i}$, which show less frequent observation of $\mathrm{RH}_{i}$ above about $130 \%$ outside of clouds in the Northern Hemisphere compared to the Southern Hemisphere, that a heterogeneous freezing mode occurs at least in some Northern midlatitude cirrus clouds (Haag et al., 2003). In addition to changing ice crystal number concentrations, heterogeneous IN have a nonlinear impact on the cirrus occurrence, optical extinction, and the fraction of clouds that are subvisible, due to the competition between the homogeneous and heterogeneous nucleation mechanisms (Haag and Kärcher, 2004).

Section 2 describes the off-line methodology used in this study. The predicted aerosol concentrations are compared with observations in Sect. 3, while Sect. 4 describes the methods used to calculate ice number concentrations and radiative effects. Section 5 reports our main results and Sect. 6 provides a discussion and our conclusions.

\section{Methodology}

We use aerosol concentrations estimated from the University of Michigan version of the LLNL Chemical Transport Model (CTM) IMPACT (Liu et al., 2005) that has been coupled to the NCAR CAM3 model (Wang et al., 2009). The monthly average aerosol concentration fields from this model are used together with fixed, off-line meteorological fields to calculate ice crystal number concentrations $\left(N_{i}\right)$ in cirrus clouds. The off-line meteorological fields include the cloud fraction and ice water content and were calculated from a simulation using the CAM3 NCAR general circulation model (Collins et al., 2004, 2006). These fields were saved every six hours, and so are generally consistent with the aerosol fields which were developed from this same meteorology.

The off-line methodology is used to calculate $N_{i}$ and the radiative impact of anthropogenic aerosols on cirrus clouds every hour. This methodology is similar to that employed by Chen and Penner (2005) in their study of aerosol effects on liquid phase clouds. The meteorological data for cloud fraction, ice water content, and liquid water content were interpolated to hourly data and were fixed in all simulations. This radiative forcing estimate is similar to the so-called Twomey effect of aerosols on warm, liquid phase clouds, since the feedbacks associated with the subsequent effects of aerosols on the sedimentation of ice crystals are not allowed to change the occurrence of ice nor is the ability of ice nuclei to form additional cirrus at lower $\mathrm{RH}_{i}$ accounted for (Liu et al., 2007, 2009; Haag and Kärcher, 2004). One advantage of avoiding these feedbacks is that the radiative forcing calculated here corresponds to that defined by the Intergovernmental Panel on Climate Change (Forster et al., 2007). While treatment of such feedbacks is desirable in global climate models, this treatment requires the development of a model with a subgrid scale parameterization of cloud fraction and supersaturation that can accurately calculate the changes to cloud occurrence associated with changes to aerosols and different ice nucleation modes. Many current global climate models do not yet have this capability. A second advantage of our approach is that small changes to ice number concentrations and to radiative forcing are not subject to variations associated with weather variations as would occur if the changes 
Table 1. Global emissions of aerosols and aerosol precursors ( $\mathrm{Tg} / \mathrm{yr}$ or $\mathrm{Tg} \mathrm{S} / \mathrm{yr}$ ).

\begin{tabular}{lrrl}
\hline Source type & Present day & Pre-industrial (1870) & Reference \\
\hline $\mathrm{SO}_{2}$ & & & \\
Fossil fuel and industry & 61.3 & 1.51 & $\begin{array}{l}\text { Smith et al. (2001) } \\
\text { Smith et al. (2004) }\end{array}$ \\
DMS & 26.1 & 26.1 & Kettle and Andreae (2000) \\
Volcanoes & 4.79 & 4.79 & Andres and Kasgnoc (1998) \\
OM & & & \\
Fossil fuel & 15.67 & 5.09 & Ito and Penner (2005) \\
Biomass burning & 47.39 & 17.91 & Ito and Penner (2005) \\
Photochemistry from terpenes & 14.5 & 14.5 & Penner et al. (2001) \\
BC & & & \\
Fossil fuel & 5.80 & 0.77 & Ito and Penner (2005) \\
Biomass burning & 4.71 & 1.75 & Ito and Penner (2005) \\
Aircraft & 0 & 2000 based on Lee et al. (2005) fuel \\
& & use model with emission factors from AERO2K \\
& $2000: 0034$ & & (Eyers et al., 2004) 1992 based on Penner et al. (1999) \\
Dust & 0.0056 & & \\
$<1.25 \mu \mathrm{m}$ & & 368 & Ginoux (2001) \\
$>1.25 \mu \mathrm{m}$ & & 1988 & Ginoux (2001) \\
Sea salt & 368 & & \\
$<1.25 \mu \mathrm{m}$ & 1988 & 543 & Internally generated using Gong et al. (1997) \\
$>1.25 \mu \mathrm{m}$ & & 2011 & Internally generated using Gong et al. (1997) \\
\hline
\end{tabular}

to ice number concentrations were allowed to change the cloud fields through changes in ice sedimentation rates and other processes. Thus, the difference in forcing associated with different aerosol emissions are all statistically significant, even if the calculations are only carried out for a single year.

We note that cirrus clouds may form in-situ from largescale uplift of air parcels and as the result of anvil detrainment from convective clouds with only about $50 \%$ of the cirrus formed by large scale uplift (Mace et al., 2006; Luo and Rossow, 2004). The ice nucleation parameterizations used here apply to cirrus formed in situ in updrafts with velocities $<$ about $1-2 \mathrm{~m} \mathrm{~s}^{-1}$ and thus are not appropriate for clouds formed in convective uplift. We saved two sets of large-scale cloud fields from the CAM model. In the first, anvil detrainment was turned off and cirrus was formed only through large-scale uplift. In the second, both anvil cirrus and cirrus from large-scale uplift were saved. The cirrus cloud fraction (cloud fraction for $T<-35^{\circ} \mathrm{C}$ ) from the first simulation was $21 \%$ on a global annual average basis while that from the second was $26 \%$. If the cloud fraction produced by largescale uplift should be only $13 \%$ (50\% of the total $26 \%$ ), then the calculated radiative forcing estimated here may be too large by of order $50 \%$. Further work is needed to adequately quantify this overestimate, but the present study shows the possible magnitude of cirrus effects.
We performed a set of model experiments in which different emissions of aerosols and aerosol precursors are used (Table 1$)$. The first simulation uses pre-industrial $(\approx 1870)$ emissions of aerosol particles and aerosol precursors. These include natural (Kettle and Andreae, 2000; Andres and Kasgnoc, 1998) and anthropogenic (Smith, et al., 2001, 2004) emissions of sulfur and soot from surface sources of biomass burning and fossil fuels (Ito and Penner, 2005), natural organic matter emissions based on a $9 \%$ conversion rate of the terpene carbon emissions from Guenther et al. (2001) to organic matter (Penner et al., 2001), dust particles for the year 2000 (P. Ginoux, personal communication, 2004) generated using the algorithm of Ginoux et al. (2001), and sea salt emissions generated internally in the model using the method of Gong et al. (1997). The second uses natural and anthropogenic particle and precursor emissions for the present day $(\approx 2000)$ for anthropogenic sulfur, anthropogenic soot from surface sources, and aircraft-generated soot. Then specific source types (soot from aircraft and from surface sources, and anthropogenic sulfate) are individually removed to examine their separate impacts on ice crystal number concentrations and radiative forcing.

These aerosol simulations were carried out using both the 3-mode version of the aerosol model in which both aerosol mass and number concentrations of sulfate aerosols are calculated as well as with a version of the model that only 
Table 2. Size distribution parameters for aerosols.

\begin{tabular}{lrrrlr}
\hline Aerosol component & Fraction & $r_{i}, \mu \mathrm{m}$ & $\sigma_{i}$ & Reference & Density $\left(\mathrm{g} / \mathrm{cm}^{3}\right)$ \\
\hline Fossil fuel and biomass OM/BC & 1.0 & 0.07 & 1.5 & Pueschel et al. (1992) & 1.5 \\
Aircraft OM/BC & 1.0 & 0.023 & 1.5 & Petzold and Schröder (1998) & 1.5 \\
Sea-salt & 0.965 & 0.035 & 1.92 & Quinn and Coffman (1998) & 2.2 \\
& 0.035 & 0.41 & 1.70 & & \\
Dust & 0.152 & 0.01 & 2.3 & De Reus et al. (2000) & 2.6 \\
& 0.727 & 0.045 & 1.6 & & 1.7 \\
Sulfate (for mass-only prediction) & 0.121 & 0.275 & 2.5 & & \\
\hline
\end{tabular}

predicts aerosol mass. As we show below, the predictions of the 3-mode model, particularly for the Aitken number concentration, are more realistic than those of the mass-only model. Moreover, the physical processes determining the sulfate aerosol number concentrations in the upper troposphere (through nucleation, condensation, and coagulation) are represented in the 3-mode model, whereas the number concentration is assumed in the mass only model (by assuming a fixed size distribution for the sulfate aerosols). Nevertheless, understanding the differences between the predictions of the mass-only model and those of the 3-mode model are of interest for comparison with coupled climate model simulations that have relied on the mass-only model for computational efficiency.

To calculate the impacts of different aerosol sources on ice crystal number concentrations, we ran the coupled IMPACT/CAM model for 5 years and used the monthly average concentrations averaged over the last 3 years for calculations of $N_{i}$ and the radiative forcing due to anthropogenic aerosols. We used two recently developed physically-based ice nucleation parameterizations (Liu and Penner, 2005; Kärcher et al., 2006) that account for the competition between homogeneous and heterogeneous nucleation to determine the ice nuclei concentrations associated with anthropogenic aerosols (see Sect. 4). The former parameterization is computationally efficient, and may therefore be useful in coupled climate/aerosol simulations. The latter parameterization calculates the supersaturation as part of an adiabatic parcel model parameterization for the probability distribution of sub-grid scale updrafts and aerosol concentrations at each grid point and is computationally demanding. Here, we emphasize the use of the Kärcher et al. (2006) since it includes an explicit representation of the relevant physics that determines the supersaturation when different aerosol types freeze in an updraft, but also show results for the Liu and Penner (2005) parameterization since it may be useful in coupled model calculations (Liu et al., 2007, 2009, see Sect. 5).

\section{Predicted aerosol concentrations}

The IMPACT aerosol model predicts the mass and number concentrations of pure (externally mixed) sulfate aerosol in the upper troposphere that result from the binary nucleation of sulfuric acid gas $\left(\mathrm{H}_{2} \mathrm{SO}_{4}(\mathrm{~g})\right)$ with $\mathrm{H}_{2} \mathrm{O}$ in either three separate modes: $r<0.005 \mu \mathrm{m}, 0.005$ to $0.05 \mu \mathrm{m}$, and $r>0.05 \mu \mathrm{m}$, or two modes: $r<0.05 \mu \mathrm{m}$ and $r>0.05 \mu \mathrm{m}$ (Wang et al., 2009). The mass concentrations of the other aerosols (which are mixed with sulfate if they have either coagulated with pure sulfate particles or have had sulfate gas condensed onto their surface) were converted to number concentrations by assuming they were externally mixed and had the log-normal size distributions given in Table 2. As noted above, we also consider a calculation in which only the mass concentrations of sulfate are predicted and number concentrations are determined by an assumed (externally mixed) size distribution.

Table 3 compares our predicted present day aerosol number concentrations in different size ranges with upper tropospheric measurements from the INCA campaign (Minikin et al., 2003) and from Clarke and Kapustin (2002). Ultrafine particles are under-predicted in both the 3-mode and massonly versions of the model, but are not expected to be activated to ice particles. These particles rapidly coagulate with both Aitken mode particles and accumulation mode particles so that the average concentrations from the model would not be expected to reproduce the largest numbers sometimes observed. The Aitken mode particle number concentrations from the 3-mode version of model simulation are a factor of two higher than the median observations in the Southern Hemisphere (SH) INCA campaign, but are in good agreement with the Northern Hemisphere $(\mathrm{NH})$ data and the tropical data from Clarke and Kapustin (2002), while accumulation mode particle concentrations are a factor of three higher than observed in the INCA campaign. The predicted accumulation mode particle number concentrations in the mass only version of the model are still high but in somewhat better agreement with the observations, while the Aitken mode number concentrations are in reasonable agreement 
Table 3a. Comparison of measured aerosol number concentrations (at STP) $\left(\mathrm{cm}^{-3}\right)$ in the upper troposphere with the 3-mode version of the model.

\begin{tabular}{ccccc}
\hline & Ultrafine & Aitken & Accumulation & Refractory \\
\hline SH & $(\mathrm{D}>0.005 \mu \mathrm{m})$ & $(\mathrm{D}>0.014 \mu \mathrm{m})$ & $(0.1<\mathrm{D}<1 \mu \mathrm{m})$ & $(\mathrm{D}>0.010 \mu \mathrm{m})$ \\
Model $^{\mathrm{a}}$ & 411 & 406 & 65 & $1(6$ with OM $)$ \\
Obs $^{\mathrm{b}}$ & $350(180-830)$ & $240(130-400)$ & $17(6-34)$ & $37(12-75)$ \\
\hline $\mathrm{NH}$ & $(\mathrm{D}>0.005 \mu \mathrm{m})$ & $(\mathrm{D}>0.014 \mu \mathrm{m})$ & $(0.1<\mathrm{D}<1 \mu \mathrm{m})$ & $(\mathrm{D}>0.010 \mu \mathrm{m})$ \\
Model $^{\mathrm{a}}$ & 680 & 670 & 129 & $6(13$ with OM $)$ \\
Obs $^{\mathrm{b}}$ & $1400(450-15000)$ & $770(290-9600)$ & $40(16-90)$ & $105(24-480)$ \\
\hline Tropics & $(0.003<\mathrm{D}<3 \mu \mathrm{m})$ & $(0.012<\mathrm{D}<3 \mu \mathrm{m})$ & & $(0.012<\mathrm{D}<3 \mu \mathrm{m})$ \\
Model $^{\mathrm{c}}$ & 3722 & 1696 & & $2(20$ with OM $)$ \\
Obs $^{\mathrm{d}}$ & $10000(500-20000)$ & $1200(400-4000)$ & & $150(50-450)$ \\
\hline
\end{tabular}

${ }^{\text {a }}$ Model concentrations are averages between 11 and $13 \mathrm{~km}$.

${ }^{\mathrm{b}}$ Observations from Minikin et al. (2003). Range represents 10 to 90 percentile.

${ }^{\mathrm{c}}$ Model concentrations are averages between 10 and $12 \mathrm{~km}, 3-14 \mathrm{~km}$ and 3-14 km for ultrafine, Aitken and refractory particles, respectively.

d Observations from Clarke and Kapustin (2002). Range is typical range or approximate standard deviation of measured concentrations at different times and locations. Ultrafine estimated from Fig. 4, Aitken and refractory from Fig. 6 in Clarke and Kapustin (2002).

Table 3b. Comparison of measured aerosol number concentrations (at STP) $\left(\mathrm{cm}^{-3}\right.$ ) in the upper troposphere with mass-only version of the model.

\begin{tabular}{ccccc}
\hline & Ultrafine & Aitken & Accumulation & Refractory \\
\hline $\begin{array}{c}\text { SH } \\
\text { Model }^{\mathrm{a}}\end{array}$ & $(\mathrm{D}>0.05 \mu \mathrm{m})$ & $(\mathrm{D}>0.014 \mu \mathrm{m})$ & $(0.1<\mathrm{D}<1 \mu \mathrm{m})$ & $(\mathrm{D}>0.010 \mu \mathrm{m})$ \\
Obs $^{\mathrm{b}}$ & $350(180-830)$ & $240(130-400)$ & $17(6-34)$ & $1(14$ with OM $)$ \\
\hline $\mathrm{NH}$ & $(\mathrm{D}>0.05 \mu \mathrm{m})$ & $(\mathrm{D}>0.014 \mu \mathrm{m})$ & $(0.1<\mathrm{D}<1 \mu \mathrm{m})$ & $(\mathrm{D}>0.010 \mu \mathrm{m})$ \\
Model $^{\mathrm{a}}$ & 658 & 599 & 107 & $7(29$ with OM $)$ \\
Obs $^{\mathrm{b}}$ & $1400(450-15000)$ & $770(290-9600)$ & $40(16-90)$ & $105(24-480)$ \\
\hline Tropics $_{\text {Model }}$ & $(0.003<\mathrm{D}<3 \mu \mathrm{m})$ & $(0.012<\mathrm{D}<3 \mu \mathrm{m})$ & & $(0.012<\mathrm{D}<3 \mu \mathrm{m})$ \\
Obs $^{\mathrm{d}}$ & $10000(500-20000)$ & $1200(400-4000)$ & & $4(31$ with OM $)$ \\
\hline
\end{tabular}

a Model concentrations are averages between 11 and $13 \mathrm{~km}$.

b Observations from Minikin et al. (2003). Range represents 10 to 90 percentile.

${ }^{\mathrm{c}}$ Model concentrations are averages between 10 and $12 \mathrm{~km}, 3-14 \mathrm{~km}$ and 3-14 km for ultrafine, Aitken and refractory particles, respectively.

$\mathrm{d}$ Observations from Clarke and Kapustin (2002). Range is typical range or approximate standard deviation of measured concentrations at different times and locations. Ultrafine estimated from Fig. 4, Aitken and refractory from Fig. 6 in Clarke and Kapustin (2002).

with the observations from the INCA campaign, but significantly smaller than the tropical data of Clarke and Kapustin (2002) (see Table 3b). We note the importance of the representation of the Aitken mode particle number concentrations since they dominated the number density of ice crystal residuals in INCA (Seifert et al., 2003).

Observations of ambient refractory particles (soot, dust and sea salt) are of order $12-450 \mathrm{~cm}^{-3}$ at STP in the upper troposphere (see Table 3), while model concentrations are only of order $1-20 \mathrm{~cm}^{-3}$. BC mass concentrations in the upper troposphere have been reported by Blake and
Kato (1995), but the uncertainties associated with these wire impactor measurements are very large (Strawa et al., 1999), and thus preclude detailed comparisons. Comparison of our calculated $\mathrm{BC}$ mass concentrations with observations by Schwarz et al. (2006) indicates that our average BC mass concentrations are about 3 times higher than the observations (Wang et al., 2009). Hence we are reasonably confident that the under-prediction of refractory particle number is not caused by an under-prediction of soot in the upper troposphere. If the observed refractory particle concentrations are associated with dust particles, the coagulation of soot with 
dust might remove soot ice nuclei on a time scale of about 10 days. We ignore this loss, since the lifetime for soot from aircraft indicates that the upper tropospheric soot aerosol lifetime is of order 6.5 days, which approximately matches the turnover time for this region from observations (Bertram et al., 2007).

Sulfur emitted by aircraft may be of order $400 \mu \mathrm{g} / \mathrm{g}$ of fuel, at least 40 times larger than typical aircraft soot emission rates. However, only a small fraction of this forms sulfate aerosols within the aircraft plume (Petzold et al., 2003; Katragkou et al., 2004), and even if the sulfate number concentrations are 10 times those of the aircraft soot concentrations (which are of order $1 \mathrm{~cm}^{-3}$ ), they are far smaller than the number concentrations of sulfate aerosols from other sources. Thus, we neglect their impact here also.

We also note that not all refractory particles would be expected to act as ice nuclei. For example, DeMott et al. (2003) and Richardson et al. (2007) report IN concentrations of $<0.01 \mathrm{~cm}^{-3}$ at STP or of order $<0.003 \mathrm{~cm}^{-3}$ at ambient conditions at cirrus temperatures in November 2001 and April and May 2004 in the free troposphere over the Western US, indicating that not all refractory particles can act as ice nuclei (if those measured during the INCA campaign are also typical for the Western US). This is consistent with the report by Seifert et al. (2003) that scavenging ratios (the fraction of ambient particles included in crystals) were $<1 \%$ in the INCA campaign. If the IN concentrations measured by DeMott et al. (2003) and Richardson et al. (2007) represent 1\% of the total refractory particles then the refractory particle concentration would be of order $1 \mathrm{~cm}^{-3}$, which is in reasonable agreement with our refractory particle number concentration. Nevertheless, we examine the sensitivity of our predicted soot forcing to changes in dust concentrations below.

\section{Methods used to calculate ice crystal number concen- tration and radiative effects}

As noted above, the predicted aerosol concentrations are used together with the IN parameterizations of Kärcher et al. (2006; hereafter KL) and Liu and Penner (2005; hereafter LP) to derive the ice crystal number concentration and effective radius, and the CAM radiative transfer model is used to calculate the difference in the top of the atmosphere (TOA) radiative flux for different cases. The KL parameterization requires a cloud parcel model simulation (with some simplifications) using the chosen updraft velocity to determine the maximum $\mathrm{RH}_{i}$ and the number of ice crystals that nucleate. We ran the parcel model starting with $100 \% \mathrm{RH}_{i}$ within cloud for the initial condition and tracked the rising parcel for $30 \mathrm{~min}$ (or until a maximum $\mathrm{RH}_{i}$ is reached, whichever is first) to determine ice nucleation. The parameterization accounts for the continuous competition between homogeneous and heterogeneous nucleation at any temperature and allows homogeneous nucleation to occur in the rising parcel even if some heterogeneous nucleation has already taken place as long as the supersaturation is able to continue to grow (see Kärcher et al., 2006). Soot and dust were set to activate at $130 \%$ in this parameterization.

The sub-grid scale variation of $\mathrm{RH}_{i}$ was calculated using the method outlined in Kärcher et al. (2006) assuming that small-scale variations of the updraft velocity $(w)$ were associated with gravity waves (Haag and Kärcher, 2004). We assume the sub-grid scale variation of $w$ has a normal probability distribution based on measurements taken during the INCA campaign (Kärcher and Ström, 2003), with a standard deviation of $0.33 \mathrm{~m} \mathrm{~s}^{-1}$. We also set the minimum updraft velocity for each grid by only using the highest fraction of velocities corresponding to the cloud fraction in the grid:

$$
\int_{w_{\min }}^{w_{\max }} n(w) d w=C F
$$

where $n(w)$ is the probability of occurrence of a given value of $w$. When the updraft velocity is larger than this minimum value, we assume the calculated $N_{i}$ represents the in-cloud value. However sensitivity tests show that the calculated ice number concentration is not very sensitive to this lower limit. $w_{\max }$ was set to $0.5 \mathrm{~m} \mathrm{~s}^{-1}$, corresponding to values typically observed in cirrus clouds formed by large-scale uplift (Gayet et al., 2006), but the forcing associated with a sensitivity study, in which $w_{\max }$ was set to $2 \mathrm{~m} \mathrm{~s}^{-1}$ and $w_{\min }$ is set to 0 is also reported. The average value of $N_{i}$ associated with the probability distribution of $N_{i}$ is calculated from:

$\bar{N}_{i}=\int_{w_{\min }}^{w_{\max }} n(w) N_{i}(w) d w / \int_{w_{\min }}^{w_{\max }} n(w) d w$.

In the original description of the LP parameterization, homogeneous nucleation only occurs if the relative humidity reaches a critical value (defined by Eq. (3.1) in LP). However, the predicted $\mathrm{RH}_{i}$ that accounts for the supersaturation developed within a rising parcel is not available for the LP parameterization in our offline simulations, so we modified the parameterization to distinguish the occurrence of homogeneous nucleation based only on temperature. Thus, if $T>T_{\text {crit_het }}$ (where $T_{\text {crit_het }}$ is given by Eq. (4.5) in LP) and $T<238 \mathrm{~K}$, we applied heterogeneous nucleation on soot particles only. If $T<T_{\text {crit_het }}-5$ we applied homogeneous nucleation on sulfate particles only. In between the two critical temperatures a linear combination of the heterogeneous and homogeneous ice number concentrations is calculated. Also, the $\mathrm{RH}_{i}$ calculated in the KL parameterization was used to calculate $N_{i}$ from deposition nucleation on dust particles. This expedient choice does not cause large differences in the calculated $N_{i}$ in the LP parameterization from that if the appropriate choice of $\mathrm{RH}_{i}$ were selected and provides a first-order measure of the indirect effect due to anthropogenic sulfate, anthropogenic soot from surface sources, and aircraft-generated soot. 
The LP parameterization as applied here uses a critical temperature (which is a function of the soot concentration and updraft velocity) to distinguish the heterogeneous regime from the homogeneous regime. The KL parameterization is more general since the heterogeneous nucleation threshold can be adjusted as new information on this threshold for different particle types becomes available. The LP parameterization is of interest since, in its current simplified form, it may be applied without any determination of the supersaturation, and is computationally much more efficient than the KL parameterization. We note that there are important differences in the parcel models on which these parameterizations were based which were pointed out by Lin et al. (2002). The KL parameterization uses a deposition coefficient of 0.5 for water vapour molecules impinging on an ice surface, while LP used 0.1. Therefore, this difference, as well as others, might explain the differences noted below. We also derived ice number concentrations with a modified version of the KL parameterization $(\mathrm{KLm})$ in which the ice nucleation properties of soot aerosols were assumed to be similar to those of sulfate, which corresponds to the recent laboratory data for soot reported by DeMott (2007).

In order to calculate the effective radius of ice crystals, we assume there is a relationship between effective radius $\left(r_{e}\right)$ and the equivalent sphere volume mean radius $\left(r_{v}\right)$ : $r_{v}^{3}=k r_{e}^{3}$. Based on the definition of $r_{e}$ and the ice crystal size distribution for $r_{e}$ given in Wyser (1998), a parameterization for the value of $k$ as a function of temperature $(T, \mathrm{~K})$ and ice water content $\left(\mathrm{IWC}, \mathrm{gm}^{-3}\right)$ can be derived: $k=\exp (a+b(T-240)+c \ln ($ IWC) $)$, in which $a=-3.15393 ; b=-0.03387$ when $T \leq 240 \mathrm{~K}$ and $b=0$ when $T>240 \mathrm{~K} ; c=-0.14738$ when $\mathrm{IWC} \leq 1 \mathrm{gm}^{-3}$ and $c=0$ when IWC $>1 \mathrm{gm}^{-3}$. Since we are only considering aerosol effects on cirrus clouds, we do not apply the parameterization in clouds with temperatures above $-35^{\circ} \mathrm{C}$. For warmer clouds, we assume a fixed effective radius: $11.8 \mu \mathrm{m}$ over ocean and $8.5 \mu \mathrm{m}$ over land (Han et al., 1994).

Changes in the effective radius of cirrus clouds impact both the shortwave and longwave radiation. In the shortwave radiation package, Raleigh scattering, absorption by ozone, water vapor and other absorptive gases, and aerosol and cloud scattering and extinction are considered (Briegleb, 1992; Collins et al., 1998, 2001). The optical depth, single scattering albedo, and asymmetry factor for ice clouds, are parameterized as a function of ice cloud effective radius (Ebert and Curry, 1992). The longwave radiation package is based on the absorptivity/emissivity formulation of Ramanathan and Downey (1986) and includes absorption by $\mathrm{CO}_{2}, \mathrm{H}_{2} \mathrm{O}$ and other greenhouse gases, as well as absorption by clouds. The maximum-random cloud overlap scheme is used (Collins et al., 2006), i.e., continuous cloud layers are assumed to be maximally overlapped, while discontinuous cloud layers are randomly overlapped.
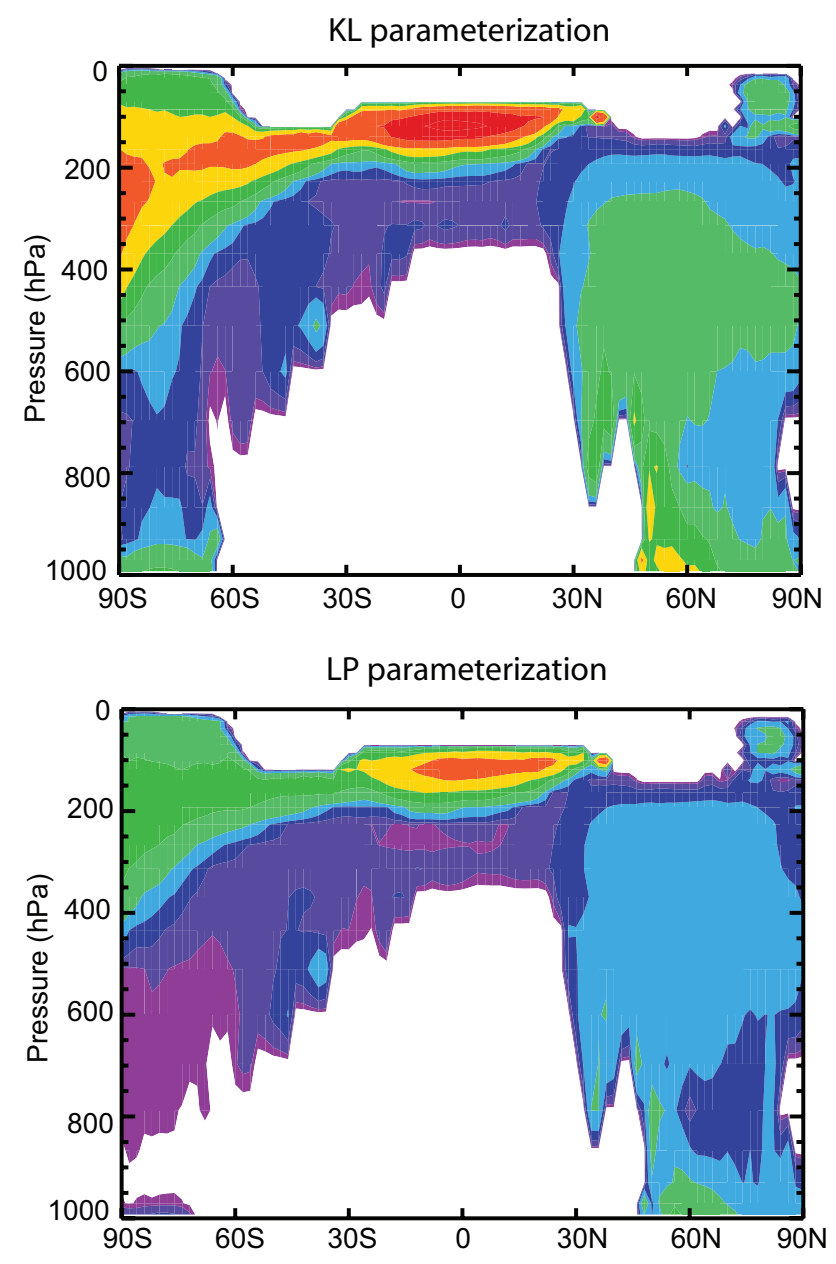

KLm parameterization

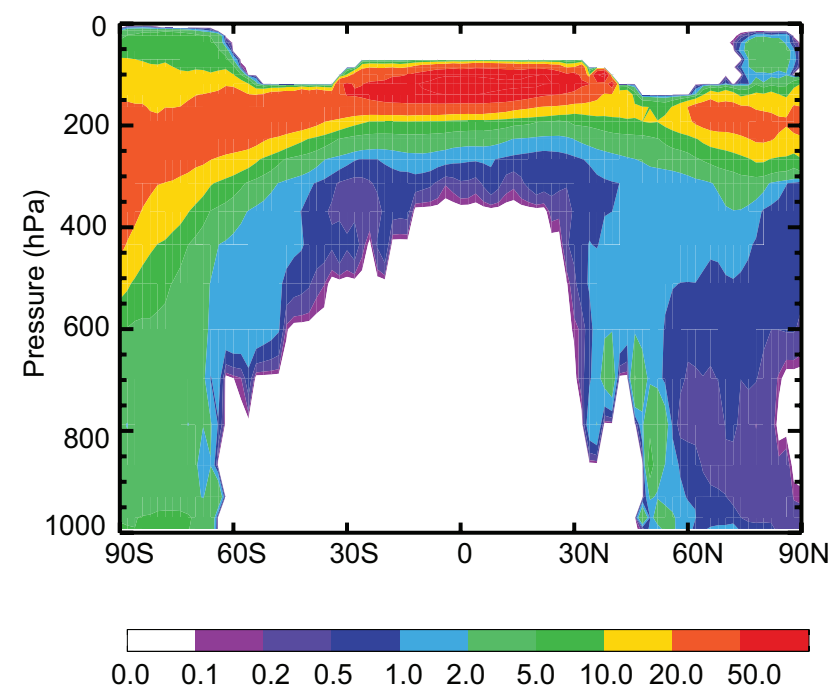

Fig. 1. Present day in-cloud ice crystal number concentrations $\left(\mathrm{cm}^{-3}\right)$ from the 3-mode model. 


\section{Results}

\subsection{Ice number concentrations}

Figure 1 shows the zonal average concentrations of in-cloud $N_{i}$ predicted for the present day. Stratus clouds colder than $238 \mathrm{~K}$ extend to the surface in polar regions and are included in our calculations. Cold clouds are also present in the CAM3 model above the tropopause, but the cloud fraction here is very small so that the grid average ice water contents are $<0.1 \mathrm{mg} \mathrm{m}^{-3}$, and their effect on forcing is very small. The ice number concentrations from the model can be compared to those taken during the INCA campaign (Gayet et al., 2006). Although ice shattering on inlet probes frequently leads to overestimates of number concentrations (McFarquhar et al., 2007), this problem does not appear to have greatly compromised the INCA measurements since most ice crystal measurements did not include any crystals larger than $500 \mu \mathrm{m}$ (Gayet et al., 2002) and any overestimate is probably less than a factor of two (Field et al., 2006; J.-F. Gayet, personal communication, 2008). Median ice number concentrations in the $\mathrm{NH}$ and $\mathrm{SH}$, near the INCA campaign (i.e. over $50 \mathrm{~N} \sim 60 \mathrm{~N}, 10 \mathrm{~W} \sim 5 \mathrm{E}, 200-400 \mathrm{hPa}$ in the $\mathrm{NH}$ and $60 \mathrm{~S} \sim 50 \mathrm{~S}, 85 \mathrm{~W} \sim 75 \mathrm{~W}, 200-400 \mathrm{hPa}$ in the SH), are of order $1.7-2.0 \mathrm{~cm}^{-3}$, and $0.2 \mathrm{~cm}^{-3}$, respectively, for the LP and KL parameterizations (with the higher $\mathrm{NH}$ estimate for the KL parameterization), while median (and the 25 and 75 percentile) observed number concentrations were 2.2 (0.84 to $4.74)$ and $1.4(0.58$ to 3.01$) \mathrm{cm}^{-3}$, respectively (Gayet et al., 2004). The NH results agree well with the INCA measurements, but the SH predicted $N_{i}$ are a factor of 10 less. However, as shown in Fig. 1 our predicted $N_{i}$ for the SH would be much closer to the observations if we had limited our model sampling to altitudes higher than $300 \mathrm{hPa}$. Ice number concentrations are larger than $20 \mathrm{~cm}^{-3}$ over much of the upper troposphere near $200 \mathrm{hPa}$ using the modified treatment of soot nucleation $(\mathrm{KLm})$, wherein soot does not nucleate at $\mathrm{RH}_{i}$ below that of sulfate. It also produces higher ice concentrations in the $\mathrm{SH}$ than those in the $\mathrm{NH}$, a finding that is not representative of the data. This occurs because of the generally lower temperatures in the $\mathrm{SH}$ which allows $\mathrm{RH}_{i}$ to be much higher causing nucleation of more small particles there. As a result, this parameterization is not considered in the following.

Figure 2 shows the latitudinal average in-cloud $N_{i}$ at three different levels for the KL and LP parameterizations for the present day (PD) and pre-industrial (PI) simulations, along with those for simulations where the emissions of anthropogenic aerosols (sulfate: $\mathrm{PD}-\mathrm{anthSO}_{4}$, surface sources of soot: PD-sBC, and aircraft soot: PD-aBC) were individually removed from the present day emissions. Ice concentrations are decreased at all latitudes as a result of present day anthropogenic emissions at 140 and $190 \mathrm{hPa}$, but are increased at $270 \mathrm{hPa}$ over Northern Hemisphere mid-latitudes. The individual perturbations are generally of the same sign though of different magnitudes in the KL and LP parameterizations. Predicted ice concentrations without anthropogenic sulfate emissions are nearly identical to the present day concentrations, though there are small differences in high altitude tropical regions, a finding also supported by the calculations in Lohmann and Kärcher (2002). Aircraft soot emissions decrease ice number concentrations at all latitudes in the KL parameterization except at Northern Hemisphere mid-latitudes where they cause increases at 190 and $270 \mathrm{hPa}$. Surface soot emissions cause similar changes in $N_{i}$ but the increases at $190 \mathrm{hPa}$ and $270 \mathrm{hPa}$ occur over most of the $\mathrm{NH}$ and there are also increases near $30^{\circ} \mathrm{S}$ at $270 \mathrm{hPa}$. In the PD simulation with the LP parameterization, increases occur as a result of surface soot emissions to $45^{\circ} \mathrm{S}$ at the $270 \mathrm{hPa}$ level. The ice number concentration decreases are similar, but somewhat larger (and increases are smaller) for the KL parameterization than for the LP parameterization.

Anthropogenic aerosols cause a decrease in $N_{i}$ at the highest altitudes (above about $200 \mathrm{hPa}$ ) which reaches of order $10 \mathrm{~cm}^{-3}$ at high latitudes in the Northern Hemisphere, and this decrease is mainly associated with aircraft soot. These regions have the lowest temperatures. The variance of $w$, which is related to gravity wave fluctuations (Haag and Kärcher, 2004), causes high values of $\mathrm{RH}_{i}$ in these regions so that homogeneous nucleation, which requires $\mathrm{RH}_{i}$ of order $160 \%$, dominates the nucleation and the development of ice crystal number concentrations in the pre-industrial atmosphere. Therefore, the addition of heterogeneous nuclei to the pre-industrial atmosphere causes a decrease in average ice number concentrations. At lower altitudes, near the northern mid-latitudes, heterogeneous ice nuclei are important to the formation of ice crystals even in the pre-industrial atmosphere, so that the addition of soot from present day sources causes an increase in average ice number concentration. By comparing the present day concentrations with the present day minus surface soot calculation or the present day minus aircraft soot calculation, one can see that the effect of surface soot is slightly larger than that of aircraft soot at $30-60 \mathrm{~N}$ and $270 \mathrm{hPa}$, but that the effect of aircraft soot is larger than surface soot at $190 \mathrm{hPa}$, the level where most aircraft soot is emitted.

Figure 3 shows the calculated probability density function for ice crystal number concentrations over the $\mathrm{NH}$ and $\mathrm{SH}$ for all simulations using the KL parameterization. These plots were developed from the average ice crystal numbers predicted from the velocity probability distribution. The probability of having ice crystal number concentrations near and above $10 \mathrm{~cm}^{-3}$ is systematically decreased in the present day simulations compared to the pre-industrial atmosphere, and the probability of occurrence of these high concentrations is similar to the present day occurrence with only sulfate, surface soot or aircraft soot removed from present day emissions. However, in regions where ice crystal number concentrations are of order $1-10 \mathrm{~cm}^{-3}$ the probability of occurrence is increased in the present day simulation compared 

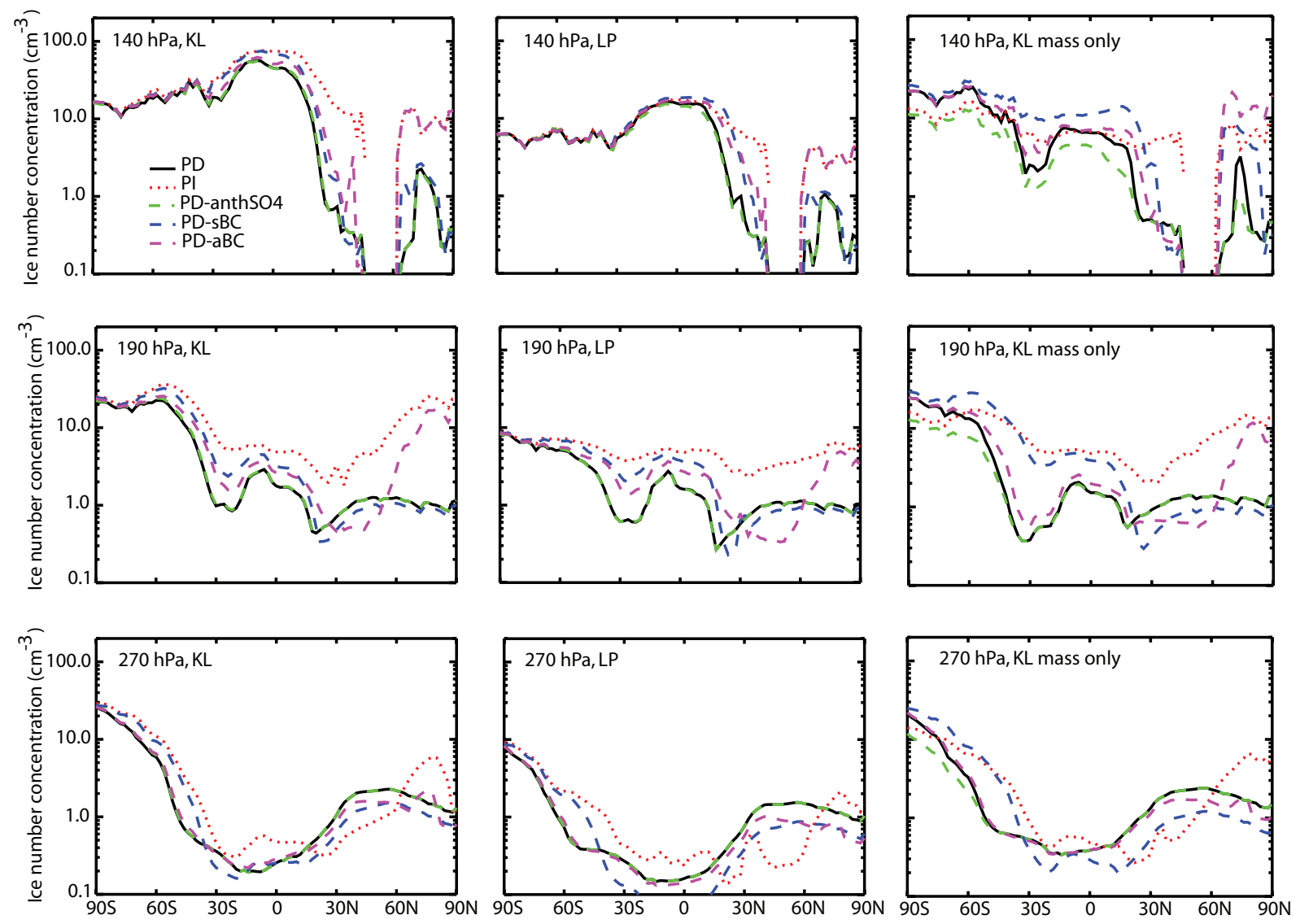

Fig. 2. Latitudinal average in-cloud ice number concentrations $\left(\mathrm{cm}^{-3}\right)$ in the 3-mode model at 3 different heights for the KL (left panel) and LP (middle panel) parameterizations. Results for the KL parameterization in the mass-only model are shown in the right panel.
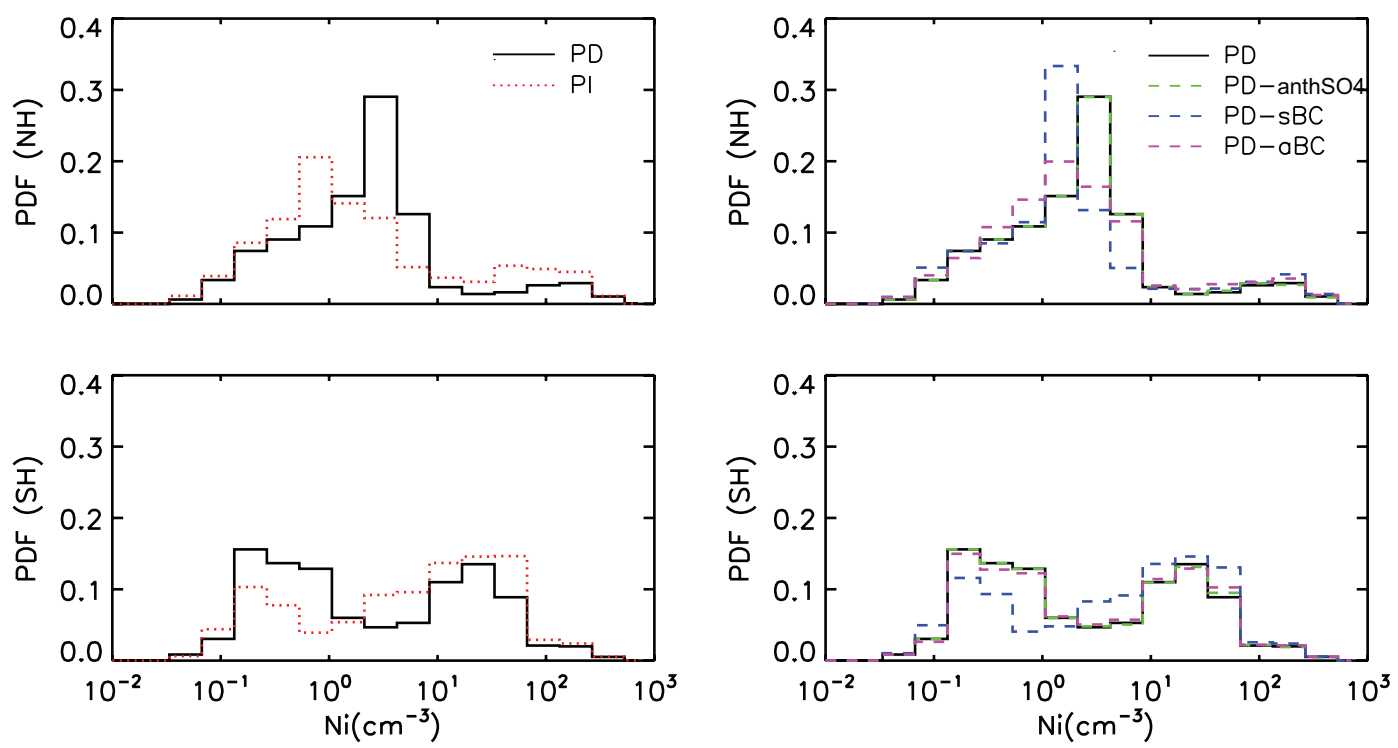

Fig. 3. Probability distribution of ice number concentrations in the Northern Hemisphere (top) and Southern Hemisphere (bottom) in model simulations with the KL parameterization. 
Table 4a. Predicted LW, SW, and net forcing $\left(\mathrm{Wm}^{-2}\right)$ in the 3-mode model. Numbers in parentheses for the KL version are from the version of the model that considered updraft velocities ranging from 0 to $2 \mathrm{~m} \mathrm{~s}^{-1}$. Numbers in parentheses for the LP version are from the model with increases in dust concentrations by a factor of about 2000 .

\begin{tabular}{|c|c|c|c|c|c|c|c|}
\hline \multirow{2}{*}{$\begin{array}{l}\text { Forcing; mass and } \\
\text { number of sulfate } \\
\text { aerosol predicted; } \\
\text { Large-scale clouds }\end{array}$} & & \multicolumn{3}{|c|}{ KL para } & \multicolumn{3}{|c|}{ LP para } \\
\hline & & Globe & $\mathrm{NH}$ & SH & Globe & $\mathrm{NH}$ & SH \\
\hline \multirow[t]{3}{*}{ All aerosols } & LW & -1.581 & -1.249 & -1.901 & -1.152 & -0.762 & -1.528 \\
\hline & SW & 0.907 & 0.855 & 0.957 & 0.627 & 0.538 & 0.713 \\
\hline & Net & $-0.674(-0.465)$ & $-0.394(-0.276)$ & $-0.945(-0.647)$ & $-0.525(-0.624)$ & $-0.224(-0.428)$ & $-0.815(-0.814)$ \\
\hline \multirow[t]{3}{*}{ Sulfate } & LW & -0.015 & -0.014 & -0.016 & 0.083 & 0.112 & 0.054 \\
\hline & SW & 0.009 & 0.012 & 0.006 & -0.045 & -0.06 & -0.03 \\
\hline & Net & $-0.006(0.013)$ & $-0.002(0.033)$ & $-0.01(-0.006)$ & $0.038(0.036)$ & $0.052(0.05)$ & $0.024(0.024)$ \\
\hline \multirow[t]{3}{*}{ Surface soot } & LW & -0.773 & -0.446 & -1.09 & -0.388 & -0.185 & -0.584 \\
\hline & SW & 0.37 & 0.263 & 0.475 & 0.128 & 0.064 & 0.191 \\
\hline & Net & $-0.403(-0.279)$ & $-0.183(-0.096)$ & $-0.615(-0.456)$ & $-0.259(-0.326)$ & $-0.121(-0.224)$ & $-0.393(-0.424)$ \\
\hline \multirow[t]{3}{*}{ Aircraft soot } & LW & -0.425 & -0.343 & -0.505 & -0.298 & -0.171 & -0.422 \\
\hline & SW & 0.264 & 0.244 & 0.284 & 0.175 & 0.127 & 0.221 \\
\hline & Net & $-0.161(-0.105)$ & $-0.099(-0.068)$ & $-0.221(-0.141)$ & $-0.124(-0.144)$ & $-0.043(-0.085)$ & $-0.201(-0.202)$ \\
\hline
\end{tabular}

to the pre-industrial simulation in the $\mathrm{NH}$ but decreased in the SH. The probability of occurrence of ice number concentrations less than $1 \mathrm{~cm}^{-3}$ is again systematically reduced in the present day simulation compared to the pre-industrial simulation in the NH, but is increased in the SH with the addition of anthropogenic aerosols. The cause of the changes in PD and PI probability of occurrence can be analyzed by examining the difference in the probability of occurrence between present day aerosols and the probability of occurrence with only sulfate, surface soot or aircraft soot removed from present day emissions. Removal of aircraft soot shifts the probability distribution to lower concentrations in the $\mathrm{NH}$, but has little effect in the SH. Removal of surface soot has an effect similar to that of aircraft soot in the NH, and a somewhat smaller effect in the SH. Removal of anthropogenic sulfate aerosol has almost no effect on the probability of occurrence of ice crystal number concentration compared to the PD simulation.

\subsection{Radiative forcing}

The changes in $N_{i}$ due to present day aerosols affect both the shortwave (SW) and longwave (LW) radiation. As noted in Fig. 2, at most NH high latitude regions at lower altitudes, $N_{i}$ increases when anthropogenic emissions are added to the PI emissions, although there are decreases above $200 \mathrm{hPa}$. These increases at lower altitudes dominate the change in the TOA SW forcing, which is generally negative north of $30^{\circ} \mathrm{N}$ latitude in both the KL and LP parameterizations (Fig. 4). Correspondingly, the TOA LW forcing is positive north of $30^{\circ} \mathrm{N}$ latitude. In the tropics the $\mathrm{SW}$ forcing is positive in both the LP and KL parameterizations. This is because the ice number concentrations decrease in the present day simulations at most altitudes (Fig. 2). Moreover, the high incident solar radiation causes large changes in the SW flux even for a small perturbation to $N_{i}$. South of 30 to $40^{\circ} \mathrm{S}$ the $\mathrm{SW}$ forcing is either small and positive (KL) or small and negative (LP). The LP parameterization has more instances where the preindustrial atmosphere is dominated by heterogeneous nucleation than that in the KL parameterization, so that adding anthropogenic aerosols can increase $N_{i}$. The sensitivity of the LW flux to small changes in $N_{i}$ is largely due to the large difference between the cloud temperature and surface temperature. The net forcing is mainly determined by the LW forcing at all latitudes, due to the high altitude of cirrus occurrence and their cold temperatures. Therefore, meteorological parameters (i.e. the temperature and the calculated maximum $\mathrm{RH}_{i}$ ) are dominant in determining the pattern of forcing by anthropogenic aerosols, so that it can be difficult to see a correlation between the forcing pattern and anthropogenic aerosol concentrations (see Fig. 6 below).

The NH, SH, and global mean values of the forcing for both the KL and LP parameterizations and all perturbations for the 3-mode model are listed in Table 4a. The total forcing from all anthropogenic aerosols ranges from -0.67 to $-0.52 \mathrm{Wm}^{-2}$ in the KL and LP parameterizations, respectively. As shown in Table $4 a$, about $70 \%$ of the total forcing is associated with surface soot. Aircraft soot results in a net negative forcing ranging from -0.16 to $-0.12 \mathrm{Wm}^{-2}$, while anthropogenic sulfate forcing is near zero, -0.01 to $+0.04 \mathrm{Wm}^{-2}$, respectively, in the two parameterizations.

In addition to the above simulations, we also expanded the range of updraft velocities from those considered in the base case (determined by the portion of the grid box associated with clouds and a maximum updraft of $0.5 \mathrm{~m} \mathrm{~s}^{-1}$ ) to the range from 0 to $2 \mathrm{~m} \mathrm{~s}^{-1}$. In all cases the global average net forcing was reduced by about $30 \%$ in the KL parameterization for all aerosol forcing and for surface and aircraft 

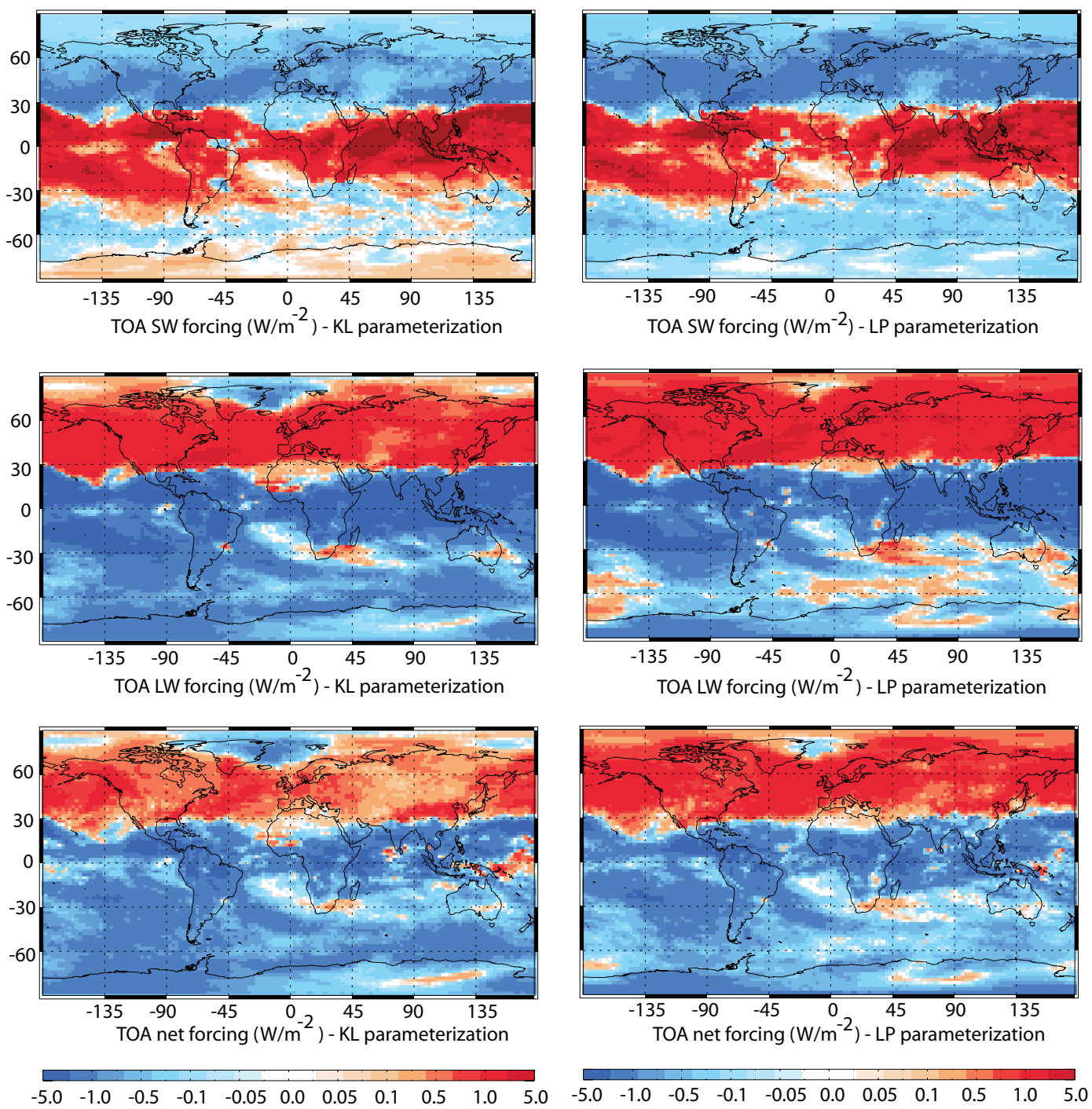

Fig. 4. Top of atmosphere present day minus pre-industrial incoming shortwave (SW), longwave (LW), and net radiative forcing for the 3-mode model using the KL (left) and LP (right) parameterizations.

soot forcing. The net forcing for sulfate actually changes sign from a negative net forcing to a positive forcing with the wider range of updraft velocities (see Table 4a). Most of the impact is the result of increasing the maximum updraft velocity to $2 \mathrm{~m} \mathrm{~s}^{-1}$. The higher range of updraft velocities allows homogeneous nucleation to dominate in more of the parcel simulations, so that the increases in $N_{i}$ caused by the addition of sulfate nuclei are larger than they are in the base case.

\subsection{Mass-only model}

For the mass-only model simulations with the KL parameterization, predicted ice crystal number concentrations are increased above $150 \mathrm{hPa}$ at most latitudes (except between 30 $70^{\circ} \mathrm{N}$ ) and are increased south of $60^{\circ} \mathrm{S}$ at all altitudes when anthropogenic sulfate aerosol is added in the PD-anthSO ${ }_{4}$ simulation (Fig. 2) rather than having almost no change as in the 3-mode version of the model. In this version of the model, the change in forcing due to homogeneous nucleation is larger than in the 3-mode simulation because the difference between the present day minus pre-industrial sulfate number concentrations in the mass-only model simulations is larger than in the 3-mode model (Fig. 5). The addition of anthropogenic sulfate increases ice crystal number concentrations while the addition of anthropogenic soot decreases $N_{i}$ at the highest altitudes, but increases $N_{i}$ at $190 \mathrm{hPa}$ and below at northern latitudes. The increase in crystal concentrations for the present-day emissions causes a positive net change in forcing for sulfate aerosols. The changes in ice crystal number concentrations associated with surface and aircraft soot 
Table 4b. Predicted LW, SW, and net forcing $\left(\mathrm{Wm}^{-2}\right)$ in the mass-only model. Numbers in parentheses used the IPCC (1999) aircraft inventory.

\begin{tabular}{|c|c|c|c|c|c|c|c|}
\hline \multirow{2}{*}{$\begin{array}{l}\text { Forcing; only aerosol } \\
\text { mass predicted; } \\
\text { Large-scale clouds }\end{array}$} & & \multicolumn{3}{|c|}{ KL para } & \multicolumn{3}{|c|}{ LP para } \\
\hline & & Globe & $\mathrm{NH}$ & $\mathrm{SH}$ & Globe & $\mathrm{NH}$ & $\mathrm{SH}$ \\
\hline \multirow[t]{3}{*}{ All aerosols } & LW & -1.047 & -0.143 & -1.92 & 0.656 & 1.481 & -0.141 \\
\hline & SW & 0.456 & 0.051 & 0.847 & -0.491 & -0.884 & -0.111 \\
\hline & Net & $-0.591(-0.498)$ & $-0.092(0.046)$ & $-1.073(-1.023)$ & 0.165 & 0.597 & -0.252 \\
\hline \multirow[t]{3}{*}{ Sulfate } & LW & 0.319 & 0.317 & 0.321 & 0.22 & 0.236 & 0.204 \\
\hline & SW & -0.153 & -0.168 & -0.137 & -0.091 & -0.108 & -0.075 \\
\hline & Net & $0.166(0.18)$ & $0.148(0.174)$ & $0.183(0.187)$ & 0.129 & 0.129 & 0.129 \\
\hline \multirow[t]{3}{*}{ Surface soot } & LW & -1.083 & -0.569 & -1.579 & 0.395 & 0.767 & 0.036 \\
\hline & SW & 0.404 & 0.215 & 0.586 & -0.382 & -0.555 & -0.215 \\
\hline & Net & $-0.642(-0.679)$ & $-0.245(-0.354)$ & $-1.025(-0.992)$ & 0.013 & 0.212 & -0.179 \\
\hline \multirow[t]{3}{*}{ Aircraft soot } & LW & -0.158 & -0.063 & -0.25 & 0.066 & 0.182 & -0.047 \\
\hline & SW & 0.081 & 0.035 & 0.125 & -0.041 & -0.099 & 0.015 \\
\hline & Net & $-0.078(0.011)$ & $-0.028(0.102)$ & $-0.126(-0.076)$ & 0.025 & 0.083 & -0.031 \\
\hline
\end{tabular}

have a similar pattern to those in the 3-mode model, though the magnitude of the $N_{i}$ change differs, causing different estimates of forcing.

There are large differences between the total forcing with the KL and LP parameterizations in the mass-only version of the model, with the net forcing ranging from -0.59 to $+0.16 \mathrm{Wm}^{-2}$, respectively. As shown in Table $4 \mathrm{~b}$, the main difference is associated with the impact of surface and aircraft soot on the forcing. The LP parameterization has smaller concentrations of ice crystals especially in the preindustrial atmosphere. When anthropogenic soot aerosols are added, the concentrations of ice crystals do not decrease as much as they do with the KL parameterization, because heterogeneous nucleation plays a larger role in determining ice concentrations in the pre-industrial atmosphere with the LP parameterization. The total forcing associated with present day aerosols ranges from -0.67 to $+0.16 \mathrm{Wm}^{-2}$, when both parameterizations and the mass-only and 3-mode simulations are considered.

\subsection{Additional sensitivity tests}

To examine the effect of differences between the simulated and observed refractory particle concentrations, we also considered a case in which dust concentrations were significantly increased over those calculated in the baseline model (shown in Table 4a for the LP parameterization). Net forcings are negative and slightly larger than those in the baseline case because the positive forcing values in the mid to high latitudes of the Northern Hemisphere decrease significantly. This is because the pre-industrial $N_{i}$ at lower altitudes (below $200 \mathrm{hPa}$ ) are significantly smaller in the base case while the present day $N_{i}$ are similar in the two cases, causing the difference in $N_{i}$ and the forcing to decrease when dust concentrations are increased. Because the global mean forcing is negative, the decrease in the positive forcing in this region causes the global mean forcing to become more negative.

We also calculated the forcing in the mass-only model with the KL simulation using the IPCC 1992 aircraft inventory (Penner et al., 1999). The calculated forcing using the older inventory is actually positive, rather than negative. Aircraft emissions in the older inventory cause somewhat larger increases in ice crystal number concentrations north of $30^{\circ} \mathrm{N}$ near $270 \mathrm{hPa}$ than in the new inventory because of slightly larger emissions (not shown).

The results from our off-line calculations may be contrasted with those from Liu et al. (2009) who calculated the forcing associated with the mass-only version of the model together with the LP parameterization in the fully-coupled IMPACT/CAM3 model. Their calculated ice crystal number concentrations are significantly smaller than those found here and their calculated forcing between PD and PI simulations is positive (of order $0.5-0.7 \mathrm{Wm}^{-2}$ ) rather than only slightly positive $\left(\approx 0.2 \mathrm{Wm}^{-2}\right.$ with the LP parameterization and mass only model) as found here. Smaller ice crystal number concentrations are expected since coagulation and sedimentation of ice crystals are included as feedbacks in the coupled climate simulation. Moreover, an increase in cloud amount is anticipated when IN are increased since these IN cause freezing at lower relative humidities than homogeneous ice nuclei (e.g. Haag and Kärcher, 2004), so the larger cloud forcing in the coupled model simulation might also be anticipated. Nevertheless, the maximum values of $\mathrm{RH}_{i}$ produced by the current version of the coupled model do not simulate the highest values recorded in the MOZAIC observations (Liu et al., 2007). This low bias may cause heterogeneous nucleation to inappropriately dominate much more frequently than 

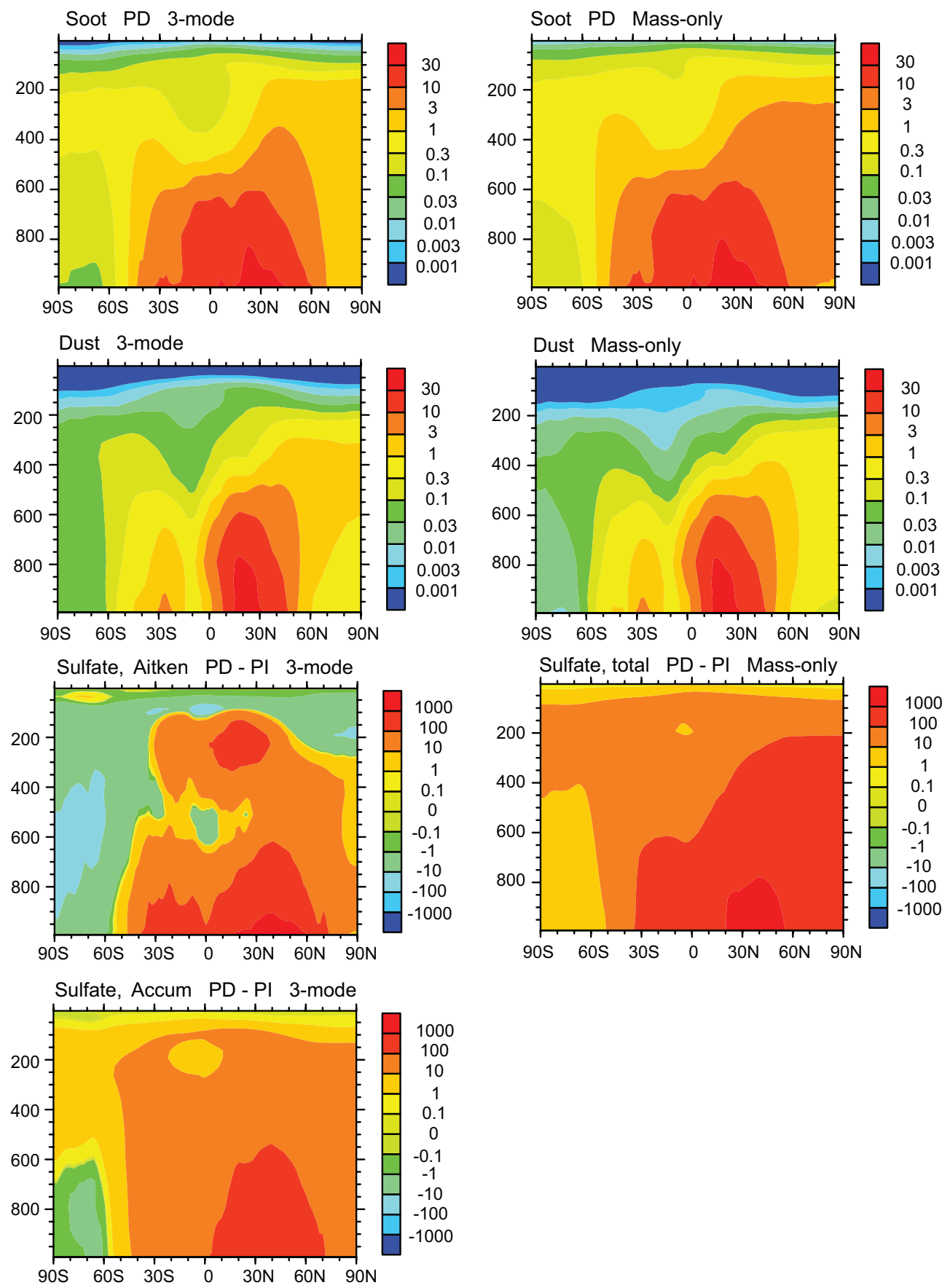

Fig. 5. Aerosol number concentrations $\left(\mathrm{cm}^{-3}\right)$ in the 3 -mode model (left) and in the mass-only model (right). Present day minus preindustrial number concentrations are shown for sulfate aerosols in the Aitken and accumulation modes for the 3-mode model.

it does in the off-line simulations reported here. Understanding the cause of the differences in these simulations is part of our on-going research.

\section{Discussion and conclusion}

Homogenous nucleation has been viewed as insensitive to aerosol concentration. Our simulations, however, show that the global mean anthropogenic sulfate net forcing can range up to $0.18 \mathrm{Wm}^{-2}$ in the version of the model in which the sulfate mass concentration, but not the number concentration, is predicted. The use of KL parameterization and LP parameterization produce similar forcing patterns for all simulations. However, because of the delicate balance between negative and positive forcing, the difference in the global 
3-mode model

Sulfate aerosol: $-0.01 \mathrm{Wm}^{-2}$
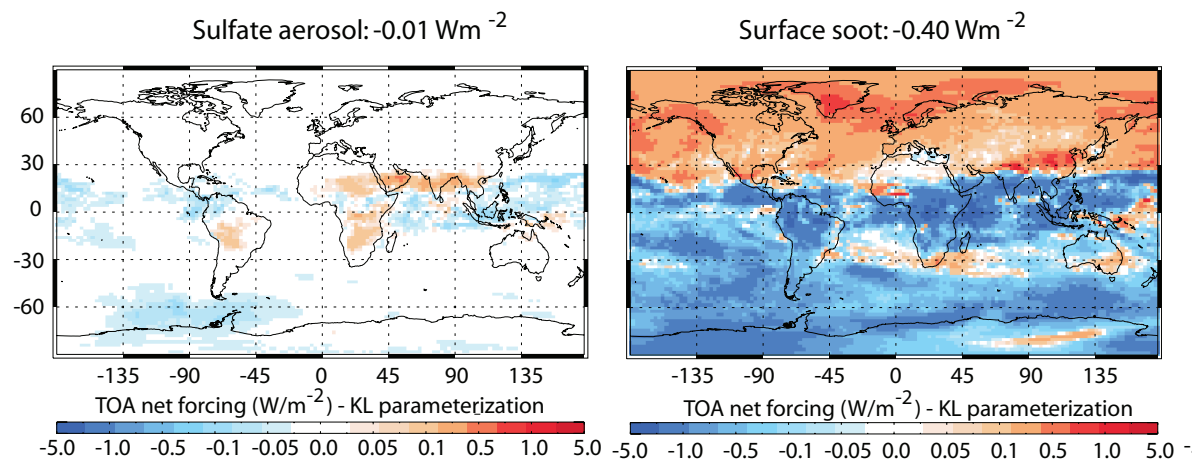

Surface soot: $-0.40 \mathrm{Wm}^{-2}$

Mass-only model

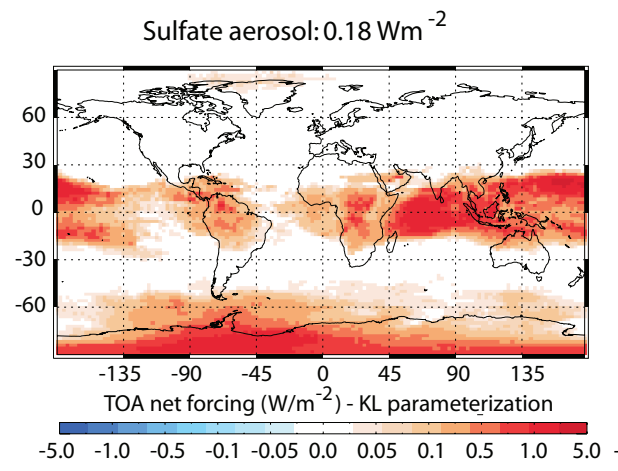

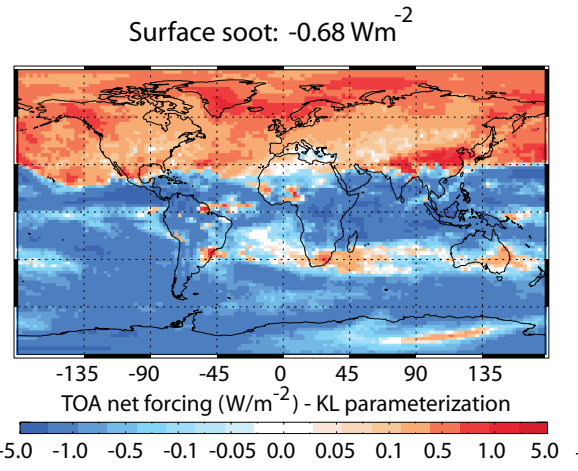

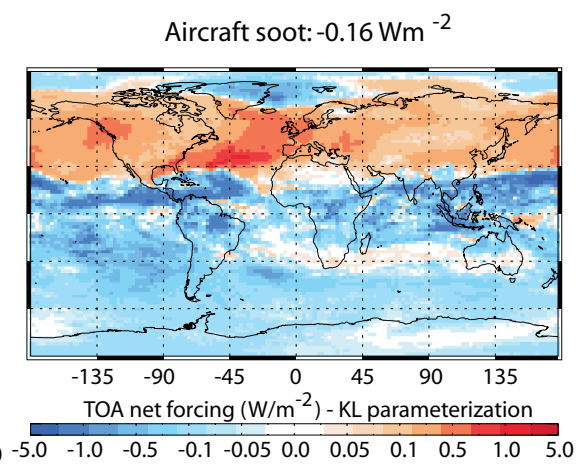

Fig. 6. Net forcing $(\mathrm{SW}+\mathrm{LW})\left(\mathrm{Wm}^{-2}\right)$ from individual aerosol components for the KL parameterization in the 3-mode and mass-only model.

mean forcing for these two parameterizations at least in the mass only version of the model can be large. The forcing by anthropogenic sulfate for the two parameterization methods is within $30 \%$ in the case of the mass only model, but is small and of opposite sign in the 3-mode model. The forcing by surface soot is within $50 \%$ in the 3 -mode model. The forcing by surface soot in the mass-only version of the aerosol model is negative in the KL parameterization and positive in the LP parameterization. We prefer the use of the 3-mode model because the calculated Aitken aerosol concentrations in this version are in better agreement with observations and because the microphysics that determines the size and number concentrations of sulfate aerosols in the upper troposphere is included in this version.

Soot particles will act as heterogeneous IN and increase the $N_{i}$ when heterogeneous nucleation dominates in the preindustrial atmosphere. But they also decrease the $\mathrm{RH}_{i}$, inhibit homogeneous nucleation, and thereby decrease $N_{i}$ when homogeneous nucleation dominates (the "negative Twomey effect"). The relative importance of these two effects is largely determined the relative occurrence of homogeneous nucleation in the pre-industrial atmosphere. As a result, our simulations show a different pattern for surface and aircraft soot forcing than for sulfate forcing, especially in the mass-only model (Fig. 6). The negative Twomey effect dominates for soot emissions causing large negative forcing in the SH for all simulations.
Homogeneous nucleation in the pre-industrial atmosphere determines the change in ice number concentration for the clouds that form between 100 and $250 \mathrm{hPa}$ and in polar regions. Heterogeneous nucleation dominates in the clouds that form between 250 and $500 \mathrm{hPa}$ in the pre-industrial atmosphere at northern mid-latitudes. Therefore, adding anthropogenic soot from surface sources decreases $N_{i}$ in high cirrus clouds, i.e., the negative Twomey effect dominates, while in low cirrus clouds, anthropogenic soot tends to increase $N_{i}$, i.e., the positive effect dominates. The patterns of both SW and LW forcing are influenced by the relative importance of these two effects. In most tropical regions, $N_{i}$ decreases so that the $\mathrm{SW}$ forcing is positive and the LW forcing is negative here, for both the 3-mode and the massonly versions of the model. In other regions, (i.e. in the $\mathrm{NH}$ mid-latitudes below $200 \mathrm{hPa}$ ) heterogeneous nucleation is already dominant in the pre-industrial simulations so that an increase in $N_{i}$ is calculated when soot aerosols are added. In these regions the $\mathrm{SW}$ forcing is negative and the LW forcing is positive. Because the LW forcing is dominant for cirrus clouds, the net forcing pattern is similar to that of the LW forcing, i.e., negative in tropical areas and in the $\mathrm{SH}$, and positive north of about $30^{\circ} \mathrm{N}$. The global mean net forcing is $-0.67 \mathrm{Wm}^{-2}$ for the KL simulation and $-0.52 \mathrm{Wm}^{-2}$ for the LP simulation for the 3-mode model. The magnitude of this forcing and its regional values (either positive or negative) are comparable to other anthropogenic forcings. The largest 
positive forcing values are in the $\mathrm{NH}$ mid-latitudes and polar regions, where the anthropogenic soot concentrations are highest, but negative forcing dominates in the tropics and $\mathrm{SH}$ mid-latitudes.

Aircraft emissions add more soot particles to the atmosphere in the $\mathrm{NH}$ upper troposphere than do surface soot emissions. These particles are coated with sulfuric acid and the forcing by these aerosols can be as large as $-0.16 \mathrm{Wm}^{-2}$. Hendricks et al. (2004) examined cases in which aircraft soot was assumed to coagulate with preexisting liquid aerosols and to decrease as a result of cloud activity. This resulted in a minimum estimate of externally mixed aircraft soot. Alternatively, they assumed that these processes did not alter the externally mixed soot number concentrations. The former case resulted in a decrease of the externally mixed aircraft soot number concentrations by about a factor of two. Hendricks et al. (2005) used the maximum calculated aircraft soot from Hendricks et al. (2004) and assumed that ice number concentrations were determined by the number of soot particles when soot and dust concentrations were above $0.5 \mathrm{~cm}^{-3}$ while below that concentration ice formed through homogeneous nucleation on sulfate particles. They did not account for the effect of variations in updraft velocity or for the continuous competition between soot and sulfate in updrafts. If only homogeneous nucleation was allowed in the background atmosphere, then aircraft soot caused a 10-40\% decrease in ice number concentrations, while if heterogeneous nucleation on surface soot and dust was allowed, then aircraft soot increased ice number concentrations by $10-40 \%$. Here, the coagulation of background sulfate with soot aerosols that takes place within the model is assumed to not change the ice formation capability of the soot aerosols, though it changes their removal by clouds (Liu et al., 2005). We included the effect of vertical velocity variations and we tested two parameterizations of ice nucleation on soot (Liu and Penner, 2005; Kärcher et al., 2006). Our global simulation shows that the effects of aircraft soot aerosol can vary significantly with altitude (Fig. 2) and this variation is determined by the relative importance of different nucleation modes as well as by the number concentration of aircraft generated soot.

In addition to the increases in $N_{i}$ at mid- to high latitudes and lower altitudes in the NH, the addition of soot from aircraft sources causes a significant (factor of 10) decrease in $N_{i}$ at high altitudes where homogeneous nucleation is important (see Fig. 2). As shown in Fig. 6, this effect is associated with a narrow band of negative forcing near north polar regions. Figure 6 shows that there are large positive forcings in the NH mid- and high latitudes, where aircraft emissions significantly increase the $N_{i}$ concentrations. Nevertheless, the global annual mean forcing is negative for aircraft soot for both the KL simulation and for the LP simulation in the 3mode model. This forcing is smaller than but comparable to the cirrus forcing due to the anthropogenic soot from surface sources.
The net TOA forcing from each simulation is dominated by $\mathrm{LW}$ radiation changes as well as by decreases in $N_{i}$ in most regions and therefore has global annual mean values that are less than zero in most simulations with the 3-mode model. Therefore, the net climate effect of anthropogenic aerosols from the "Twomey" effect on cirrus clouds is to cool the surface. The calculated global mean net forcing due to anthropogenic sulfate aerosols is small and close to zero, -0.01 to $0.04 \mathrm{Wm}^{-2}$. The soot indirect forcing from surface sources and from aircraft sources ranges from -0.26 to $-0.40 \mathrm{Wm}^{-2}$ and from -0.12 to $-0.16 \mathrm{Wm}^{-2}$, respectively.

Since the change in cirrus clouds and their radiative properties due to anthropogenic emissions largely depends on which nucleation mode is dominant, the estimation of the pre-industrial IN in the upper troposphere is very important. The transition from homogeneous to heterogeneous nucleation occurs over a narrow range of IN concentrations (Gierens, 2003), so that the IN calculated in the PI emissions determines the dominance of different nucleation modes, thereby affecting the effect of adding anthropogenic aerosols. Important uncertainties in the calculation of aerosol effects on cirrus still remain. Dust particle concentrations in the upper troposphere in our model do not dominate our predicted refractory particle (or IN) concentrations. Increases in the latter, however, even by a factor of 100 (to match observations) would only have a small effect on the radiative forcing associated with anthropogenic aerosols if they act as deposition nuclei.

We have not calculated the effects of soot addition to cloud occurrence and cloud fraction. If cloud fraction increases as a result of increases in IN, the negative forcing noted above could be substantially mitigated.

In summary, the global pattern of TOA forcing due to anthropogenic aerosols is a result of several factors, including the number and ice nucleation efficiency of the PI and present day aerosols, the updraft velocity, cloud microphysics (which depends on the $T$ and $\mathrm{RH}_{i}$ ), cloud macrophysics (i.e. the cloud fraction and ice water path), and the incident solar radiation. Each of these factors must be accounted for in order to determine the magnitude and the pattern of forcing.

Acknowledgements. We are grateful for support by the NSF climate dynamics program as well as the NASA IDS program under grant numbers ATM 0333016 and NNG04GC01G, respectively. The Pacific Northwest National Laboratory is operated for the DOE by Battelle Memorial Institute under contract DE-AC06-76RLO 1830.

Edited by: R. MacKenzie

\section{References}

Andres, R. J. and Kasgnoc, A. D.: A time-averaged inventory of subaerial volcanic sulfur emissions, J. Geophys. Res., 103(D19), 25251-25261, 1998. 
Archuleta, C. M., DeMott, P. J., and Kreidenweis, S. M.: Ice nucleation by surrogates for atmospheric mineral dust and mineral dust/sulfate particles at cirrus temperatures, Atmos. Chem. Phys., 5, 2617-2634, 2005, http://www.atmos-chemphys.net/5/2617/2005/.

Blake, D. F. and Kato, K.: Latitudinal distribution of black carbon soot in the upper troposphere and lower stratosphere, J. Geophys. Res., 100(D4), 7195-7202, 1995.

Briegleb, B. P.: Delta-Eddington approximation for solar radiation in the NCAR Community Climate Model, J. Geophys. Res., 97, 7603-7612, 1992.

Chen, Y. and Penner, J. E.: Uncertainty analysis for estimates of the first indirect aerosol effect, Atmos. Chem. Phys., 5, 2935-2948, 2005 , http://www.atmos-chem-phys.net/5/2935/2005/.

Clarke, A. and Kapustin, V. N.: A Pacific Aerosol Survey, Part I: A Decade of Data on Particle Production, Transport, Evolution, and Mixing in the Troposphere, J. Atmos. Sci., 59, 363-382, 2002.

Collins, W. D.: A global signature of enhanced shortwave absorption by clouds, J. Geophys. Res., 103, 31669-31679, 1998.

Collins, W. D.: Parameterization of generalized cloud overlap for radiative calculations in general circulation models, J. Atmos. Sci., 58, 3224-3242, 2001.

Collins, W. D., Rasch, P. J., Boville, B. A., et al.: Description of the NCAR Community Atmosphere Model (CAM3.0), Tech. Rep. NCAR/TN-464+STR, 2004.

Collins, W. D., Rasch, P. J., Boville, B. A., Hack, J. J., Mccaa, J. R., Williamson, D. L., Briegleb, B. P., Bitz, C. M., Lin, S.-J., and Zhang, M.: The Formulation and Atmospheric Simulation of the Community Atmosphere Model Version 3 (CAM3), J. Climate, 19, 2144-2161, 2006.

DeMott, P. J.: An exploratory study of ice nucleation by soot aerosols, J. Appl. Meteorol., 29, 1072-1079, 1990.

DeMott, P. J., Meyers, M. P., and Cotton, W. R.: Parameterization and impact of ice initiation processes relevant to numericalmodel simulations of cirrus clouds, J. Atmos. Sci, 51(1), 77-90, 1994.

DeMott, P. J., Rogers, D. C., and Kreidenweis, S. M.: The susceptivility of ice formation in upper tropospheric clouds to insoluble aerosol components., J. Geophys. Res., 102, 19575-19584, 1997.

DeMott, P. J., Chen, Y., Kreidenweis, S. M., Roger, D. C., and Shermann, D. E.: Ice formation by black carbon particles, Geophys. Res. Lett., 26, 2429-2432, 1999.

DeMott, P. J., Cziczo, D. J., Prenni, A. J., Murphy, D. M., Kreidenweis, S. M., Thomson, D. S., Borys, R., and Rogers, D. C.: Measurements of the concentration and composition of nuclei for cirrus formation, P. Natal. Acad. Sci. USA, 100, 14655-14660, 2003.

DeMott, P. J.: Progress and Issues in Quantifying Ice Nucleation Involving Atmospheric Aerosols, presented at the 17th International Conference on Nucleation and Atmospheric Aerosols, Galway, Ireland, 13-17 August, 2007.

de Reus, M., Dentener, F., Thomas, A., Borrmann, S., Ström, J., and Lelieveld, J.: Airborne observations of dust aerosol over the North Atlantic Ocean during ACE 2: Indications for heterogeneous ozone destruction, J. Geophys. Res., 105, 15263-15275, 2000.

Ebert, E. E. and Curry, J. A.: A parameterization of ice-cloud optical-properties for climate models, J. Geophys. Res., 97(D4), 3831-3836, 1992.

Eyers, C. J., Norman, P., Middel, J., Plohr, M., Michot, S., Atkinson, K., and Christou, R. A.: AERO2k Global Aviation Emissions Inventories for 2002 and 2025, QinetiQ/4/01113, online available at: http://www.cate.mmu.ac.uk/ reports_aero2k.asp?chg=projects\&chg $2=2\rangle$ http://www.cate. mmu.ac.uk/reports_aero $2 \mathrm{k}$.asp? $\mathrm{chg}=$ projects $\& \operatorname{chg} 2=2, \quad$ last access: January 2009, 2004.

Field, P. R., Heymsfield, A. J., and Bansemer, A.: Shattering and particle interarrival times measured by optical array probes in ice clouds, J. Atmos. Ocean. Tech., 23, 1357-1371, 2006.

Field, P. R., Möhler, O., Connolly, P., Krämer, M., Cotton, R., Heymsfield, A. J., Saathoff, H., and Schnaiter, M.: Some ice nucleation characteristics of Asian and Saharan desert dust, Atmos. Chem. Phys., 6, 2991-3006, 2006, http://www.atmos-chem-phys.net/6/2991/2006/.

Forster, P., Ramaswamy, V., Artaxo, P., et al.: Chapter 2, Changes in Atmospheric Constituents and in Radiative Forcing, in: Climate Change 2007: The Physical Science Basis, edited by: Solomon, S., Qin, D., Manning, M., et al., Cambridge University Press, Cambridge, UK, 129-234, 2007.

Gayet, J.-F., Auriol, F., Minikin, A., Ström, J., Seifert, M., Krejci, R., Petzold, A., Febvre, G., and Schumann, U.: Quantitative measurement of the microphysical and optical properties of cirrus clouds with four different in situ probes: Evidence of small ice crystals, Geophys. Res. Lett., 29(24), 2230, doi:10.1029/2001GL014342, 2002

Gayet, J.-F., Ovarlez, J., Shcherbakov, V., Ström, J., Schumann, U., Minikin, A., Auriol, F., Petzold, A., and Monier, M.: Cirrus cloud microphysical and optical properties at southern and northern midlatitudes during the INCA experiment, J. Geophys. Res., 109, D20206, doi:10.1029/2004JD004803, 2004.

Gayet, J.-F., Shcherbakov, V., Mannstein, H., Minikin, A., Schumann, U., Ström, J., Petzold, A., Ovarlez, J., and Immler, F.: Microphysical and optical properties of midlatitude cirrus clouds observed in the southern hemisphere during INCA, Q. J. Roy. Meteor. Soc., 132, 2719-2748, 2006.

Gierens, K.: On the transition between heterogeneous and homogeneous freezing, Atmos. Chem. Phys., 3, 437-446, 2003, http://www.atmos-chem-phys.net/3/437/2003/.

Ginoux, P., Chin, M., Tegen, I., Prospero, J. M., Holben, B., Dubovik, O., and Lin, S.-J.: Sources and distributions of dust aerosols simulated with the GOCART model, J. Geophys. Res., 106, 20255-20274, 2001.

Gong, S. L., Barrie, L. A., and Blanchet, J.-P.: Modeling sea-salt aerosols in the atmosphere 1. Model development, J. Geophys. Res., 102, 3805-3818, 1997.

Gorbunov, B., Baklanov, A., Kakutkina, N., Windsor, H. L., and Toumi, R.: Ice nucleation on soot particles, J. Aerosol Sci., 32, 199-215, 2001.

Guenther, A., Hewitt, C. N., Erickson, D., Fall, R., Geron, C., Graedel, T., Harley, P., Klinger, L., Lerdau, M., McKay, W. A., Pierce, T., Scholes, B., Steinbrecher, R., Tallamraju, R., Taylor, J., and Zimmerman, P.: A global model of natural volatile organic compound emissions, J. Geophys. Res., 100, 8873-8892, 1995.

Han, Q. Y., Rossow, W. B., and Lacis, A. A.: Near-global survey of effective droplet radii in liquid water clouds using ISCCP data, 
J. Climate, 7(4), 465-497, 1994.

Haag, W., Kärcher, B., Ström, J., Minikin, A., Lohmann, U., Ovarlez, J., and Stohl, A.: Freezing thresholds and cirrus cloud formation mechanisms inferred from in situ measurements of relative humidity, Atmos. Chem. Phys., 3, 1791-1806, 2003, http://www.atmos-chem-phys.net/3/1791/2003/.

Haag, W. and Kärcher, B.: The impact of aerosols and gravity waves on cirrus clouds at midlatitudes, J. Geophys. Res., 109, D12202, doi:10.1029/2004JD004579, 2004.

Hendricks, J., Kärcher, B., Lohmann, U., and Ponater, M.: Do aircraft black carbon emissions affect cirrus clouds on the global scale?, Geophys. Res. Lett., 32(12), 2005.

Heymseld, A. J. and Miloshevich, L. M.: Homogeneous ice nucleation and supercooled liquid water in orographic wave clouds, J. Atmos. Sci., 50(15), 2335-2353, 1993.

Hung, H.-M., Malinowski, A., and Martin, S. T.: Kinetics of heterogeneous ice nucleation on the surfaces of mineral dust cores inserted into aqueous ammonium sulfate particles, J. Phys. Chem. A., 107, 1296-1306, 2003.

Ito, A. and Penner, J. E.: Historical emissions of carbonaceous aerosols from biomass and fossil fuel burning for the period 1870-2000, Global Biogeochem. Cy., 19(2), GB2028, doi:10.1029/2004GB002374, 2005.

Jensen, E. J. and Toon, O. B.: Ice nucleation in the upper troposphere - sensitivity to aerosol number density, temperature, and cooling rate, Geophys. Res. Lett., 21(18), 2019-2022, 1994.

Jensen E. J., Toon, O. B., Westphal, D. L., Kinne, S., and Heysmfield, A. J.: Microphysical modeling of cirrus, 1. Comparison with 1986 fire IFO measurements, J. Geophys. Res., 99, 1042110442, 1994.

Kärcher, B. and Lohmann, U.: A parameterization of cirrus cloud formation: Homogeneous freezing of supercooled aerosols, J. Geophys. Res., 107, 4010, doi:10.1029/2001JD000470, 2002.

Kärcher, B., Hendricks, J., and Lohmann, U.: Physically based parameterization of cirrus cloud formation for use in global atmospheric models, J. Geophys. Res., 111(D1), D01205, doi:10.1029/2005JD006219, 2006.

Kärcher, B. and Ström, J.: The roles of dynamical variability and aerosols in cirrus cloud formation, Atmos. Chem. Phys., 3, 823838, 2003, http://www.atmos-chem-phys.net/3/823/2003/.

Katragkou, E., Wilhelm, S., Arnold, F., and Wilson, C. W.: First gaseous Sulfur (VI) measurements in the simulated internal flow of an aircraft gas turbine engine during project PartEmis, Geophys. Res. Lett., 31, 2117, doi:10.1029/2003GL018231, 2004.

Kettle, A. J. and Andreae, M. O.: Flux of dimethylsulfide from the oceans: A comparison of updated data seas and flux models, J. Geophys. Res., 105(D22), 26793-26808, 2000.

Koop, T., Ng, H. P., Molina, L. T., and Molina, M. J.: A new optical technoque to study aerosol phase transitions: The nucleation of ice from $\mathrm{H}_{2} \mathrm{SO}_{4}$ aerosols, J. Phys. Chem. A., 102, 8924-8931, 1998.

Lee, D. S., Owen, B., Graham, A., Fichter, C., Lim, L. L., and Dimitriu, D.: Study of the allocation of aviation emissions from scheduled air traffic - present day and historical, Final Report to DEFRA Global Atmosphere Division, Manchester Metropolitan University, 62 pp., online available at: http://www.cate.mmu.ac. uk/project_view.asp?chg=projects $\&$ chg $2=2 \& i d=2$, last access: January 2009, 2005.

Lin, R.-F., Starr, D. O.'C., Demott, P. J., Cotton, R., Sassen, K.,
Jensen, E., Kärcher, B., and Liu, X.: Cirrus parcel model comparison project. Phase 1: The critical components to simulate cirrus initiation explicitly, J. Atmos. Sci., 59, 2305-2329, 2002.

Liu, X. and Penner, J. E.: Ice nucleation parameterization for a global model, Meteorologische Zeitschrift, 14(4), 499-514, 2005.

Liu, X., Penner, J. E., and Herzog, M.: Global modeling of aerosol dynamics: Model description, evaluation and interactions between sulfate and non-sulfate aerosols, J. Geophys. Res., 110, D18206, doi:10.1029/2004JD005674, 2005.

Liu, X., Penner, J. E., Ghan, S. J., and Wang, M.: Inclusion of Ice Microphysics in the NCAR Community Atmospheric Model Version 3 (CAM3), J. Climate, 20, 4520-4547, 2007.

Liu, X., Penner, J. E., and Wang, M.: Influence of Anthropogenic Sulfate and Black Carbon on Upper Tropospheric Clouds Using the NCAR CAM3 Coupled with a Global Aerosol Model, J. Geophys. Res., online available at: http://www.agu.org/journals/ jd/papersinpress.shtml\#, doi:10.1029/2008JD010492, in press, 2009.

Lohmann, U. and Kärcher, B.: First interactive simulations of cirrus clouds formed byhomogeneous freezing in the ECHAM general circulation model, J. Geophys. Res., 107(D10), 4105, doi:10.1029/2001JD000767, 2002.

Luo, Z. and Rossow, W. B.: Characterizing Tropical Cirrus Life Cycle, Evolution, and Interaction with Upper-Tropospheric Water Vapor Using Lagrangian Trajectory Analysis of Satellite Observations, J. Climate, 17, 4541-4563, 2004.

Mace, G. G., Deng, M., Soden, B., and Zipser, E.: Association of Tropical Cirrus in the 10-15-km Layer with Deep Convective Sources: An Observational Study Combining Millimeter Radar Data and Satellite-Derived Trajectories, J.Atmos.Sci., 63, 480 503, 2006.

McFarquhar, G., Um, J., Freer, M., Baumgardner, D., Kok, G. L., and Mace, G.: Importance of small ice crystals to cirrus properties: Observations from the Tropical Warm Pool International Cloud Experiment (TWP-ICE), Geophys. Res. Lett., 34, L13803, doi:10.1029/2007GL029865, 2007.

Minikin, A., Petzold, A., Ström, J. Krejci, R., Seifert, M., van Velthoven, P., Schlager, H., and Schumann, U.: Aircraft observations of the upper tropospheric fine particle aerosol in the Northern and Southern Hemispheres at midlatitudes, Geophys. Res. Lett., 30(10), 1503, doi:10.1029/2002GL016458, 2003.

Möhler, O., Büttner, S., Linke, C., Schnaiter, M., Saathoff, H., Stetzer, O., Wagner, R., Krämer, M., Mangold, A., Ebert, V., and Schurath, U.: Effect of sulphuric acid coating on heterogeneous ice nucleation by soot aerosol particles, J. Geophys. Res., 110, D11210, doi:10.1029/2004JD005169, 2005.

Möhler, O., Field, P. R., Connolly, P., Benz, S., Saathoff, H., Schnaiter, M., Wagner, R., Cotton, R., Krämer, M., Mangold, A., and Heymsfield, A. J.: Efficiency of the deposition mode ice nucleation on mineral dust particles, Atmos. Chem. Phys., 6, 3007-3021, 2006, http://www.atmos-chem-phys.net/6/3007/2006/.

Notholt, J., Luo, B. P., Fueglistaler, S., Weisenstein, D., Rex, M., Lawrence, M. G., Bingemer, H., Wohltmann, I., Corti, T., Warneke, T., von Kuhlmann, R., and Peter, T.: Influence of tropospheric $\mathrm{SO}_{2}$ emissions on particle formation and the stratospheric humidity, Geophys. Res. Lett., 32, L07810, doi:10.1029/2004GL022159, 2005. 
Penner, J. E., Lister, D., Griggs, D., Docken, D., and MacFarland, M.: Aviation and the Global Atmosphere, Intergovernmental Panel on Climate Change Special Report, Cambridge University Press, Cambridge, UK, 1999.

Petzold, A. and Schröder, F. P.: Jet engine exhaust aerosol characterization, Aerosol Sci. Tech., 28, 62-76, 1998.

Petzold, A., Stein, C., Nyeki, S., Gysel, M., Weingartner, E., Baltensperger, U., Giebl, H., Hitzenberger, R., Döpelheuer, A., Vrchoticky, S., Puxbaum, H., Johnson, M., Hurley, C. D., Marsh, R., and Wilson, C. W.: Properties of jet engine combustion particles during the PartEmis experiment: Microphysics and Chemistry, Geophys. Res. Lett., 30(13), 1719, doi:10.1029/2003GL017283, 2003.

Pueschel, R. F., Blake, D. F., Snetsinger, K. G., Hansen, A. D. A., Verma, S., and Kato, K.: Black carbon (soot) aerosol in the lower stratosphere and upper troposphere, Geophys. Res. Lett., 19, 1659-1662, 1992.

Quinn, P. K. and Coffman, D. J.: Local closure during the First Aerosol Characterization Experiment (ACE 1): Aerosol mass concentration and scattering and backscattering coefficients, J. Geophys. Res., 103, 16575-16596, 1998.

Ramanathan, V. and Downey, P.: A nonisothermal emissivity and absorptivity formulation for water vapor, J. Geophys. Res., 91, 8649-8666, 1986.

Richardson, M. S., DeMott, P. J., Kreidenweis, S. M., Cziczo, D. J., Dunlea, E. J., Jimenez, J. L., Thomson, D. S., Ashbaugh, L. L., Borys, R. D., Westphal, D. L., Casuccio, G. S., and Lersch,T. L.: Measurements of heterogeneous ice nuclei in the western United States in springtime and their relation to aerosol characteristics, J. Geophys. Res., 112, D02209, doi:10.1029/2006JD007500, 2007.

Salam, A., Lohmann, U., Crenna, B., Lesins, G., Klages, P., Rogers, D., Irani, R., MacGillivray, A., and Coffin, M.: Ice nucleation studies of mineral dust particles with a new continuous flow diffusion chamber, Aerosol Sci. Tech., 40, 134-143, 2006.

Schwarz, J. P., Gao, R. S., Fahey, D. W., Thomson, D. S., Watts, L. A., Wilson, J. C., Reeves, J. M., Darbeheshti, M., Baumgardner, D. G., Kok, G. L., Chung, S. H., Schulz, M., Hendricks, J., Lauer, A., Kärcher, B., Slowik, J. G., Rosenlof, K. H.,
Thompson, T. L., Langford, A. O., Loewenstein, M., and Aikin, K. C.: Single-particle measurements of midlatitude black carbon and light-scattering aerosols from the boundary layer to the lower stratosphere J. Geophys. Res., 111(D16), D16207, doi:10.1029/2006JD007076, 2006.

Seifert, M., Ström, J., Krejci, R., Minikin, A., Petzold, A., Gayet, J.F., Schumann, U., and Ovarlez, J.: In-situ observations of aerosol particles remaining from evaporated cirrus crystals: Comparing clean and polluted air masses, Atmos. Chem. Phys., 3, 10371049, 2003, http://www.atmos-chem-phys.net/3/1037/2003/.

Smith, S., Andres, R., Conception, L., and Lurz, J.: Historical sulfur dioxide emissions 1850-2000: Methods and results, JGCRI Research report PNNL 14537, Paciific Northwest National Laboratory, Richland, WA, USA, 16 pp., online available at: http://www.pnl.gov/main/pulications/external/technical reports/PNNL14537.pdf, 2004.

Smith, S. J., Pitcher, H., and Wigley, T. M. I.: Global and regional anthropogenic sulfur dioxide emissions, Global Planet. Change, 29, 99-119, 2001.

Strawa, A. W., Drdla, K., Ferry, G. V., Verma, S., Pueschel, R. F., Yasuda, M., Salawitch, R. J., Gao, R. S., Howard, S. D., Bui, P. T., Loewenstein, M., Elkins, J. W., Perkins, K. K., and Cohen, R.: Carbonaceous aerosol (Soot) measured in the lower stratosphere during POLARIS and its role in stratospheric photochemistry, J. Geophys. Res., 104(D21), 26753-26766, 1999.

Wang, M., Penner, J. E., and Liu, X.: The coupled IMPACT aerosol and NCAR CAM3 climate model: Evaluation of aerosol fields and uncertainties associated with the simulation of predicted aerosol number and size distribution, J. Geophys. Res., online available at: http://www.agu.org/journals/jd/papersinpress. shtml\#, doi:10.1029/2008JD010459, in press, 2009.

Wyser, K.: The effective radius in ice clouds, J. Climate, 11, 1793 $1802,1998$.

Zuberi, B., Betram, A. K., Cassa, C. A., Molina, L. T., and Molina, M. J.: Heterogeneous nucleation of ice in $\mathrm{H}_{2} \mathrm{SO}_{4}-\mathrm{H}_{2} \mathrm{O}$ particles with mineral dust immersions, Geophys. Res. Lett., 29(10), 1504, doi:10.1029/2001GL014289, 2002. 